\title{
CFD Simulation of Anaerobic Digester with Variable Sewage Sludge Rheology
}

\author{
K.J. Craig ${ }^{\mathrm{a},}{ }^{*}$, M.N. Nieuwoudt ${ }^{\mathrm{b}}$, L.J.Niemand ${ }^{\mathrm{c}}$ \\ ${ }^{a}$ Thermoflow Research Group, Department of Mechanical and Aeronautical Engineering, University of Pretoria, \\ Private Bag X20, Hatfield, 0028, South Africa.+27-12-420-3515 ken.craig@up.ac.za \\ ${ }^{b}$ Westinghouse Electric South Africa, Centurion, South Africa. mnnieu@gmail.com \\ ${ }^{c}$ Shosalowe Inv, Leeuwfontein, Pretoria, South Africa. jurieniemand@mweb.co.za \\ * Corresponding author
}

\section{Abstract}

A computational fluid dynamics (CFD) model that evaluates mechanical mixing in a full-scale anaerobic digester was developed to investigate the influence of sewage sludge rheology on the steady-state digester performance. Mechanical mixing is provided through an impeller located in a draft tube. Use is made of the Multiple Reference Frame model to incorporate the rotating impeller. The non-Newtonian sludge is modeled using the Hershel-Bulkley law because of the yield stress present in the fluid. Water is also used as modeling fluid to illustrate the significant non-Newtonian effects of sewage sludge on mixing patterns. The variation of the sewage sludge rheology as a result of the digestion process is considered to determine its influence on both the required impeller torque and digester mixing patterns. It was found that when modeling the fluid with the HershelBulkley law, the high slope of the sewage stress-strain curve at high shear rates causes significant viscous torque on the impeller surface. Although the overall fluid shear stress property is reduced during digestion, this slope is increased with sludge age, causing an increase in impeller torque for digested sludge due to the high strain rates caused by the pumping impeller. Consideration should be given to using the Bingham law to deal with high strain rates. The overall mixing flow patterns of the digested sludge do however improve slightly. 


\section{Keywords}

CFD; digester; Hershel-Bulkley law; impeller mixing; viscous torque; sludge rheology

\section{Nomenclature}

CFD computational fluid dynamics

D Diameter, $\mathrm{m}$

EPA Environmental Protection Agency

G Average velocity gradient, $\mathrm{s}^{-1}$

$k \quad$ consistency coefficient, Pa. $s^{n}$

LES large eddy simulation

MRF multiple reference frame

$N \quad$ rotation speed, RPM

n power law index

RANS Reynolds-averaged Navier Stokes

Re Reynolds number

SMM sliding mesh method

SST shear stress transport

TS total solids concentration, $\%$

$V_{a} \quad$ average draft tube velocity, $\mathrm{m} / \mathrm{s}$

VOF volume of fluid 


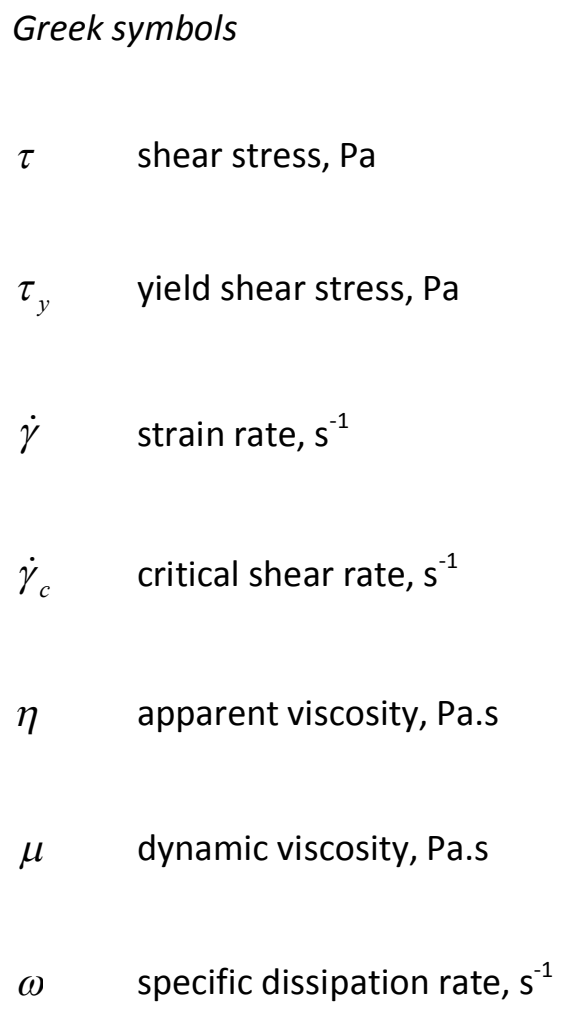

\section{Introduction}

The anaerobic digestion process is widely used to treat biodegradable materials such as domestic sewage, agricultural manure and food waste. The biodegradable material (sewage sludge in this study) is broken down by microorganisms in the absence of oxygen. A significant part of the organic solids in sewage sludge is decomposed to form other organic and inorganic compounds in dissolved form. This biological transformation has a strong influence on the rheological characteristics of the sludge (Monteiro, 1997). A useful by-product of this process is the generation of biogases such as methane and carbon dioxide leading to an increased interest in anaerobic digestion as part of a renewable energy solution.

Computational Fluid Dynamics (CFD) is increasingly used to model anaerobic digester performance. Wu (2010a) simulated mechanical draft tube mixing in an egg-shaped digester containing dairy cow manure sludge (using properties from Achkari-Begdouri and Goodrich, 1992). The same fluid was 
used by Wu and Chen (2008) for cylindrical digesters using pumped mixing, and Yu et al. (2011) who considered mechanical mixing using an axial flow impeller and a helical ribbon. Their modeling fluid was a non-Newtonian sludge modeled by a power law whose coefficients were determined by a rheological experiment. Bridgeman (2012) modeled a cylindrical digester stirred by two six-blade paddles, again using the same dairy cow liquid manure properties as $\mathrm{Wu}$ (2010a). Wu (2010a), Yu et al. (2011) and Bridgeman (2012) used the MRF (Multiple Reference Frame) approach in ANSYS Fluent (2010) to model the relative rotation of the impellers/stirrers in the computational domain. Meroney (2009) used water (Newtonian) as modeling fluid for dilute sludge and simplified the effect of impellers in draft tubes using fan boundary conditions. Terashima et al. (2009) used an imposed body force to simulate the effect of a downward-pumping screw located in a draft tube. Their study is the only digester CFD simulation in the literature that assumed laminar flow.

Wu (2011) asserted that most digester applications are turbulent and used Large Eddy Simulation (LES) (Wu, 2012a) and a range of 12 turbulence models ( $\mathrm{Wu}, 2010 \mathrm{~b})$ to evaluate different turbulence closure methods. Of the Reynolds-Averaged Navier-Stokes (RANS) models, the standard k- $\omega$ performed the best. The high cost of LES limited the investigation as to the improved turbulent resolution that can be obtained with this model (Wu, 2010b). In evaluating a gas-mixed digester, Wu (2010a) decided on the SST k- $\omega$ turbulence model for modeling gas mixing. Bakker et al. (2009) found that the SST k- $\omega$ turbulence model performed the best in the modeling of an agitated nonNewtonian slurry.

When modeling the motion of an impeller or stirrer in a bioreactor or chemical reactor, the incorporation of the mechanical mixer can be done in different ways. Apart from the MRF approach and simplified actuator plane methods (e.g., fan boundary condition, imposed body force) mentioned above, a more accurate but more computationally intensive method is the Sliding Mesh Model (SMM), as implemented, e.g., in ANSYS Fluent (2010). Kritzinger (2010) compared the MRF method to the SMM and found that the MRF method provided reliable engineering answers in a 
much shorter time (mainly because the MRF allows for a steady-state solution while the SMM method is inherently transient). In that study, the impeller interacted with stationary blades in a stirrer reactor. The exact nature of the mechanical mixing configuration does determine the influence of an MRF implementation. E.g., Bakker et al. (2009) modeled a pitch-blade turbine impeller agitating a non-Newtonian slurry (modeled as a Hershel-Bulkley law fluid) with a straightbladed stator located in close proximity to the impeller. Because of the small gap between the impeller and stator, they found that the MRF approach couldn't capture the strong time-dependent interaction between the two as the SMM could. In the current application, the impeller is situated in a stationary draft tube providing a constant axi-symmetric boundary that enhances the ability of the MRF method to accurately model the steady-state situation. Wu (2011) used the SMM for the LES simulations in that study, and since large-eddy simulations are inherently transient, the additional cost of the SMM was not that much of a factor. Although the LES-SMM results were better than the RANS-MRF results in that study, the slight increase in accuracy was judged not to be justified by the considerable increase in computational effort.

This paper evaluates an anaerobic digester situated in a municipal waste water treatment plant. The work was prompted by the retrofitting of existing, old digesters with new mixing equipment. It is therefore important that the CFD modeling provides confidence of the mixing performance of the digester as well as gives an indication of the power required by the impeller/draft tube combination. Because of the fact that the digester modification has not been implemented, full-scale validation is not possible. Of the CFD digester studies in literature, only Terashima et al. (2009) report full-scale results in the form of a tracer experiment. Lab-scale digester validation has been performed by other researchers using CFD simulation (e.g., Bridgeman, 2012; Meroney, 2009; Yu et al., 2011) or through the use of simpler geometries like non-Newtonian pipe flow (Wu and Chen, 2008) or water agitated in a tank with a Rushton turbine ( $\mathrm{Wu}, 2010 \mathrm{c})$. In general, these validation exercises show that CFD modeling is capable of predicting digester mixing and performance provided that modeling features like grid independency, proper rheological treatment and impeller rotation are treated correctly. 
Domestic sewage or sludge exhibits yield stress behavior (Monteiro, 1997) and as such is better modeled using the Hershel-Bulkley or Bingham laws. The power law used for liquid manure in the CFD studies mentioned above is therefore not applicable in that it assumes zero yield stress in the non-Newtonian fluid. In addition, Monteiro (1997) showed that the rheological properties of sewage sludge change during the digestion process. For batch operation, this means that the power consumed by the impeller will change during operation and for sizing purposes, the maximum torque and power needs to be known. For continuous feed digesters, the sludge in the digester has a variation in age. For this reason, rheological properties ranging from raw to digested sludge are used in the study to investigate this effect.

The paper starts with describing the theoretical model used for the CFD simulation, followed by a description of the rheological properties implemented. The geometric description and meshing strategy used is explained next, thereafter CFD model settings like turbulence modeling, boundary conditions used and the MRF approach are discussed. After a presentation of mixing criteria, results are presented. These take the form of a grid independence study, an evaluation of free-surface motion on the results, the effect of sewage sludge age on the torque required for turning the impeller, and an overall discussion of digester mixing patterns. Conclusions conclude the paper.

\section{Theoretical model}

The commercial CFD code ANSYS Fluent (v.13.0, v.14.0 and v.14.5) is used to determine the steadystate iso-thermal turbulent flow in the digester through solution of the Navier-Stokes equations (continuity and conservation of momentum). The following sections discuss different aspects of the theoretical model. 


\subsection{Rheological properties}

Domestic sludge seems to be better described by the Hershel-Bulkley law (Monteiro, 1997), which is a combination of the power law and the Bingham law. The Hershel-Bulkley law allows for shearthinning or shear-thickening after yield, depending on the power law index being less or more than one, respectively. Both the Hershel-Bulkley and Bingham laws have a yield stress that needs to be overcome before the fluid comes into motion.

Bingham law:

Hershel-Bulkley law:

$$
\tau=\tau_{y}+\mu_{p} \dot{\gamma}
$$

$$
\tau=\tau_{y}+k \dot{\gamma}^{n}
$$

$$
\eta=\frac{\tau_{y}}{\dot{\gamma}}+k \dot{\gamma}^{n-1}
$$

where $\tau$ is the shear stress, $\dot{\gamma}$ the strain or shear rate and $\eta$ the apparent viscosity. The parameters yield stress $\left(\tau_{y}\right)$, consistency coefficient $(k)$, plastic viscosity $\left(\mu_{\mathrm{p}}\right)$ and power-law index $(n)$ are determined experimentally. It can be seen that the Bingham law corresponds to the Hershel-Bulkley law with $n=1$.

In the implementation in ANSYS Fluent (2010), a critical shear rate parameter, $\dot{\gamma}_{c}$, is added to avoid infinite apparent viscosities at very low shear rates (due to the discontinuity at $\dot{\gamma}=0$ in equation (3)). It is implemented via a switch between the linear stress-strain region and the shear thinning/thickening portion in the following manner:

For $\dot{\gamma} \leq \dot{\gamma}_{c}: \eta=\frac{\tau_{y}\left(2-\frac{\dot{\gamma}}{\dot{\gamma}_{c}}\right)}{\dot{\gamma}_{c}}+k\left[(2-n)+(n-1) \frac{\dot{\gamma}}{\dot{\gamma}_{c}}\right]$

For $\dot{\gamma}>\dot{\gamma}_{c}: \eta=\frac{\tau_{y}}{\dot{\gamma}}+k\left(\frac{\dot{\gamma}}{\dot{\gamma}_{c}}\right)^{n-1}$ 
Equation (4) reduces to equation (3) at $\dot{\gamma}=\dot{\gamma}_{c}$. Some researchers assume a constant value for the apparent viscosity below the critical shear rate instead of the linear relationship shown in equation (4). E.g., Bakker et al. (2009) adjust this critical apparent viscosity (and hence the shear rate) until their simulated results correspond to experimental predictions. As the data measured in Monteiro (1997) extend down to a lower shear rate limit of $0.01 \mathrm{~s}^{-1}$, this value is used for the critical shear rate in the current study, except for the first case listed in Table 1 , where $0 \mathrm{~s}^{-1}$ is used, implying that only equation (5) is used in the model. To illustrate the difference between the Monteiro (1997) data (for 3-4\% total solids (TS) by weight when raw) and the $5.4 \%$ TS liquid dairy cow manure used by Wu (2010a), refer to Figure 1 where the shear stress versus shear rate is plotted on a log-log scale. Both raw (0 days) and digested (40 days) sludge data from Monteiro (1997) are shown together with Hershel-Bulkley law fits that most closely resemble the single experiment measured data (coefficients also presented in Table 1). At diminishing shear rates (as found in the body of the digester), the sewage sludge reaches a constant yield stress that decreases with sludge age. For liquid manure, the shear stress required diminishes towards zero as the shear rate is reduced (similar to that shown in Figure 1 for water at $20^{\circ} \mathrm{C}$, for comparison). At high shear rates however (as are found on the surfaces of the impeller and draft tube), a high shear stress is required to bring the non-Newtonian fluid into motion. The slope of this curve at high shear rates increases with sewage sludge age (Monteiro, 1997), implying that digested sludge remains difficult to pump using an impeller but that the bulk digester fluid that experiences low shear rates is more easily kept in motion (lower shear stress required). Data from Baudez et al. (2011) who only consider digested sewage sludge are also plotted in Figure 1 . Their $1.85 \%$ total solids concentration (when digested) data match very well with that of Monteiro.

Table 1 also lists the Hershel-Bulkley coefficient data for raw sludge based on Monteiro's own data fits for both his experiments (the raw sludge total solids concentration differed for the two 
experiments listed (Monteiro (1997)). This coefficient set was used for all simulations except those evaluating the effect of sludge age (see Results section).

\begin{tabular}{|l|l|l|l|l|}
\hline Sludge age [days] & Yield stress, $\tau_{y}$ & Power-law index, & Consistency \\
index, $k\left[\mathrm{~Pa} \cdot \mathrm{s}^{\mathrm{n}}\right]$ & $\dot{\gamma}_{c}\left[\mathrm{~s}^{-1}\right]$ \\
\hline $\begin{array}{l}\mathrm{Pa}] \\
\text { data fits) }\end{array}$ & 0.9 & 0.5 & 0.5 & 0 \\
\hline $\begin{array}{l}0 \text { (single experiment } \\
\text { result) }\end{array}$ & 0.7 & 0.66 & 0.75 & 0.01 \\
\hline $\begin{array}{l}40 \text { (single experiment } \\
\text { result) }\end{array}$ & 0.3 & 1.15 & & \\
\hline
\end{tabular}

Table 1 - Hershel-Bulkley law coefficients for sewage sludge (based on Monteiro (1997))

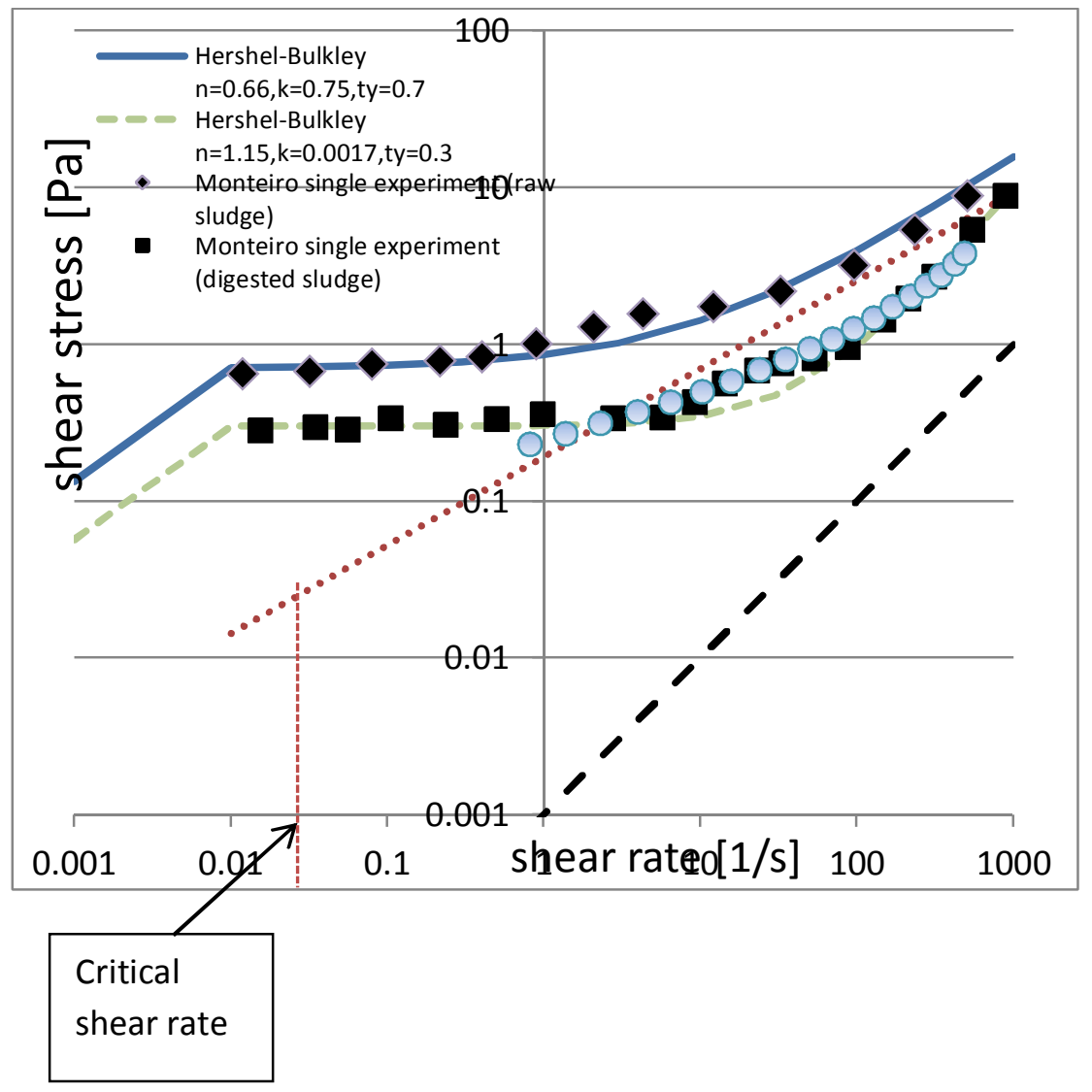

Figure 1- Rheological properties of sewage sludge (Monteiro, 1997), liquid manure (Achkari-Begdouri and Goodrich, 1992), digested sludge (Baudez et al., 2011) and water with Hershel-Bulkley law fits for sewage sludge 


\subsection{Geometry and meshing}

The geometry and meshes were generated using GAMBIT v.2.4.6. Various meshes were constructed to obtain a mesh independent solution. The CFD model domain is displayed in Figure 2, with only the fluid part being modeled. The characteristics of the digester are listed in Table 2. The upper boundary is the assumed free-surface position. The draft tube that contains a triple helix blade impeller near its top is located centrally in the digester. The draft tube supports (see insert in Figure 2) are neglected in the model. The free-surface is assumed to be flat for most of the simulations (see exception later under the Results section).

\begin{tabular}{|l|l|}
\hline Digester volume $\left[\mathrm{m}^{3}\right]$ & 1250 \\
\hline Draft tube diameter [m] & 0.61 \\
\hline Impeller rotation rate [RPM] & 500 \\
\hline Digester internal diameter [m] & 13.5 \\
\hline Draft tube exit below free & 0.3 \\
surface [m] & \\
\hline Impeller (top) position below & 0.8 \\
free surface [m] & \\
\hline
\end{tabular}

Table 2 - Digester characteristics 


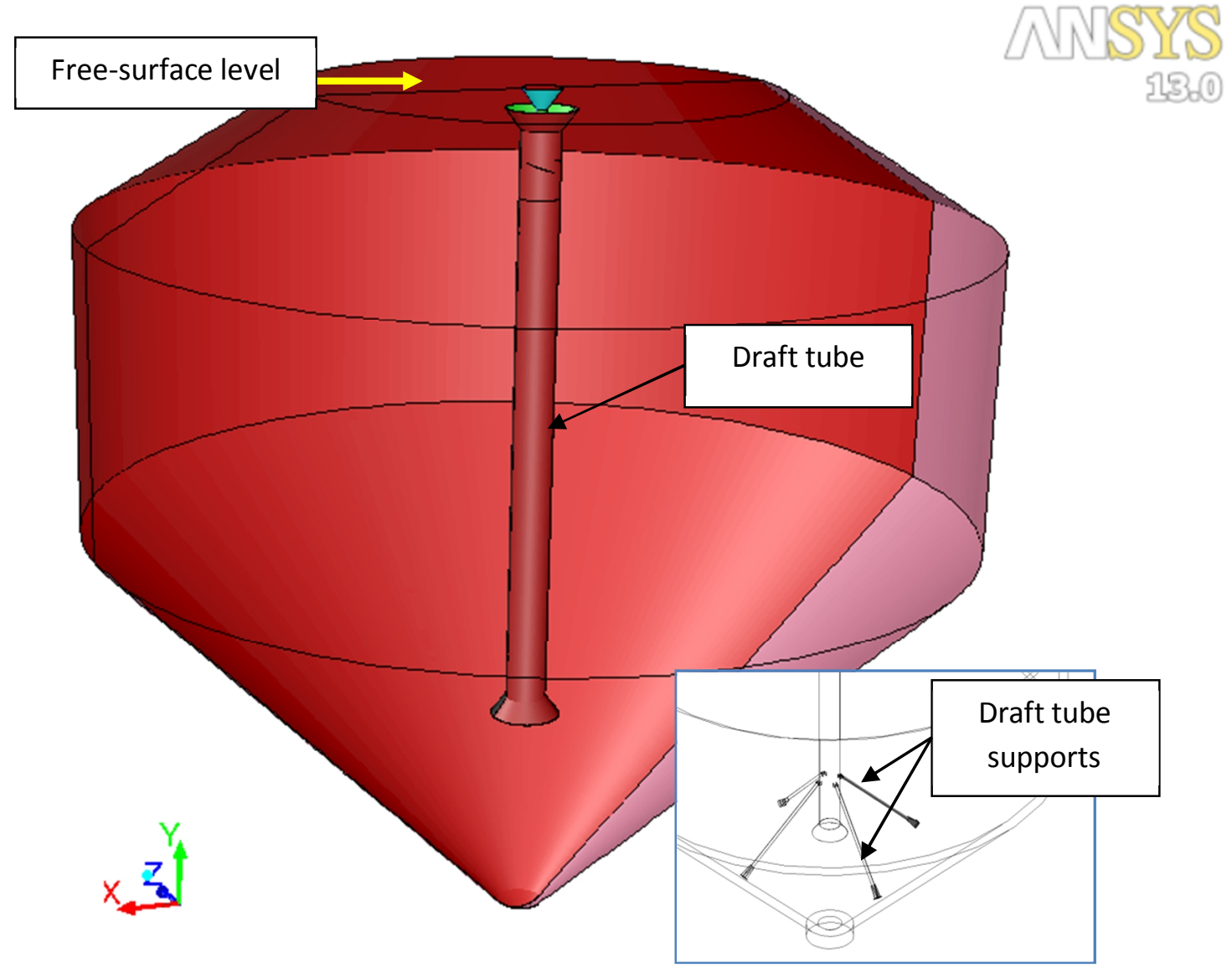

Figure 2 - CFD model geometry of digester and draft tube

Two draft tube configurations were modeled. First a stationary cone-shaped flow deflector was modeled at the exit of the draft tube to deflect the swirling impeller flow sideways (Figure 3). This type of deflector could cause a hydraulic jump in the free surface of the digester (the free-surface treatment is discussed under the Results section). To allow more gradual turning of the flow, a bellmouth-shaped rotating flow deflector was also considered (Figure 4).

The domain was meshed with mixed cells (hexahedral, tetrahedral and prisms). Cells were concentrated in the impeller area and draft tube inlet and outlet where the highest gradients are expected. To allow illustration of mesh independence in the results, a coarse ( 4.8 million cells), a medium (10.4 million cells) and a fine mesh ( 23 million cells) were generated, with a refinement ration of 2.2. The Grid Convergence Index (GCI) method (Roach, 1998; ASME V\&V 20, 2009) was used to quantify mesh independence (see section 2.7). The CFD simulation with the fine mesh took 
about 1 week to reach convergence (about 40000 iterations) on a 64-core cluster. The coarse, medium and fine mesh models are compared side-by-side in Figure 5 for the draft tube exit area. The draft tube thickness of $5 \mathrm{~mm}$ is included in the model, with different mesh densities on either side of the draft tube, as shown. The difference mesh sizes were obtained by changing key mesh size parameters. E.g., the impeller minimum mesh size ranged from $2 \mathrm{~mm}$ for the fine mesh, $5 \mathrm{~mm}$ for the medium mesh and $8 \mathrm{~mm}$ for the coarse mesh. Figure 6 compares the impeller surface meshes. The digester maximum mesh size ranged from $100 \mathrm{~mm}$ for the fine mesh, $150 \mathrm{~mm}$ for the medium mesh and $200 \mathrm{~mm}$ for the coarse mesh. In addition to the meshes mentioned above, a 2D axi-symmetric mesh of 336 thousand cells was generated to investigate free-surface movement due to the impeller in a Volume-of-Fluid (VOF) model (see Results section). This transient axi-symmetric model included a layer of air above the sludge, and was solved with gravity enabled and an initial condition assuming $100 \%$ sludge phase below the initial free-surface position and $0 \%$ sludge phase above.

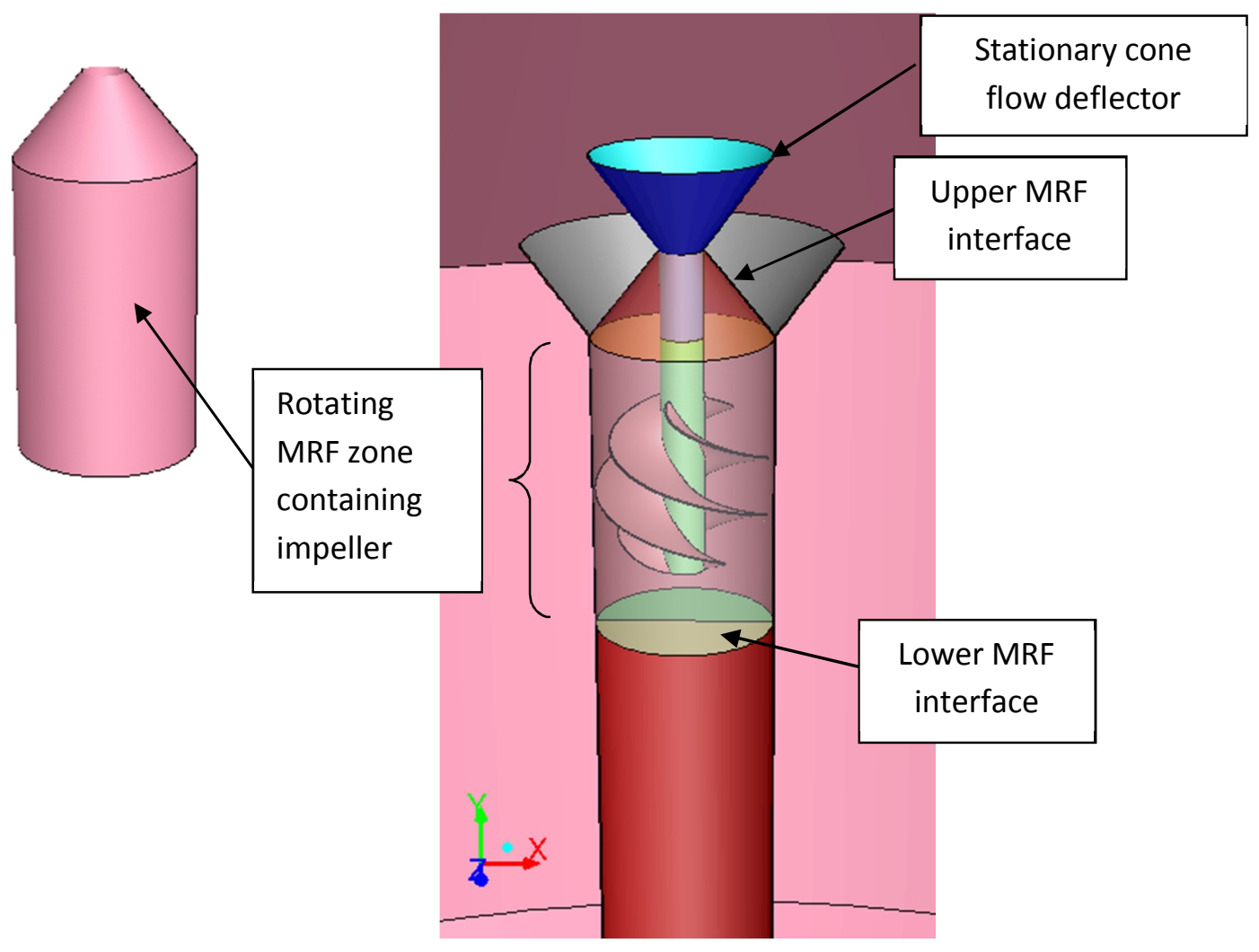

Figure 3 - Impeller in draft tube with cone-shaped deflector 


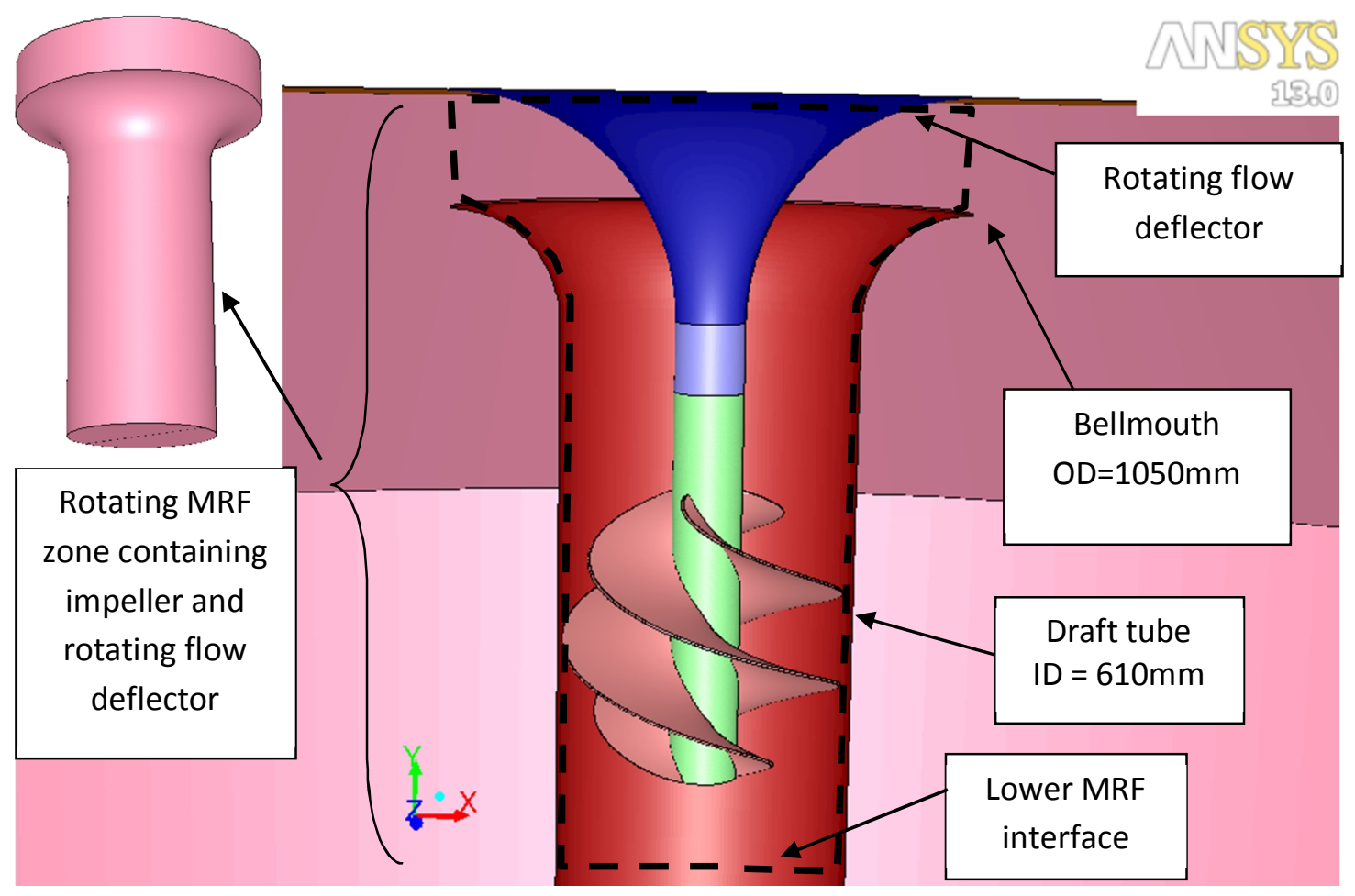

(a)

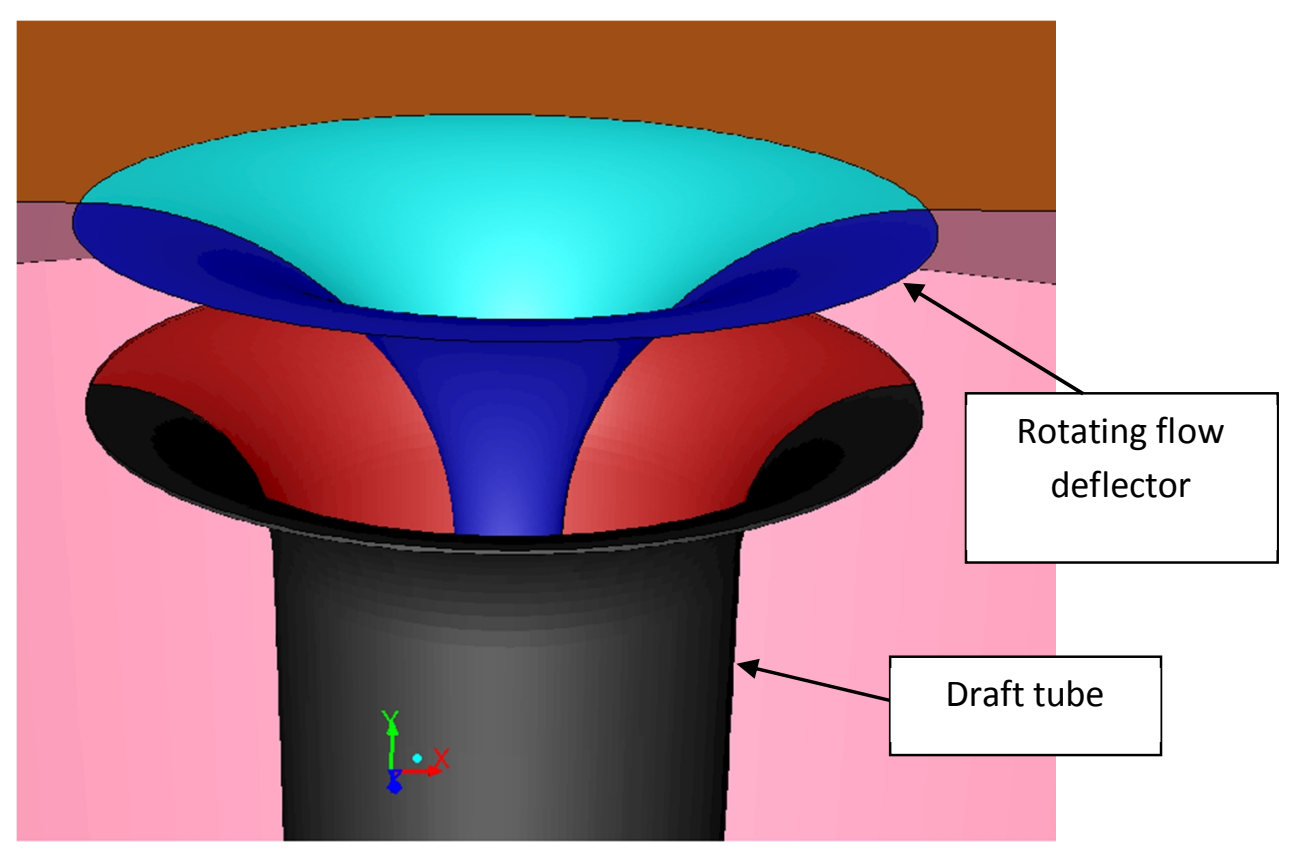

(b)

Figure 4-Impeller in draft tube with bell-mouth exit and flow deflector (a) Side view, and (b) View of draft tube exit flow gap 


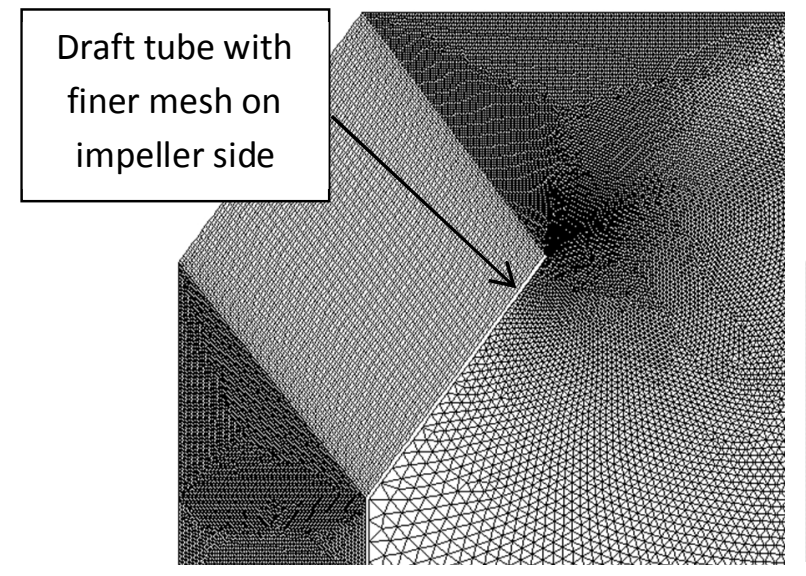

(a)

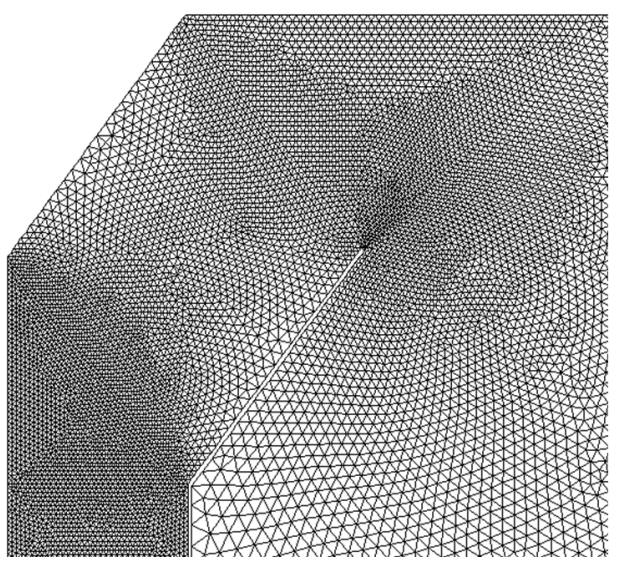

(b)

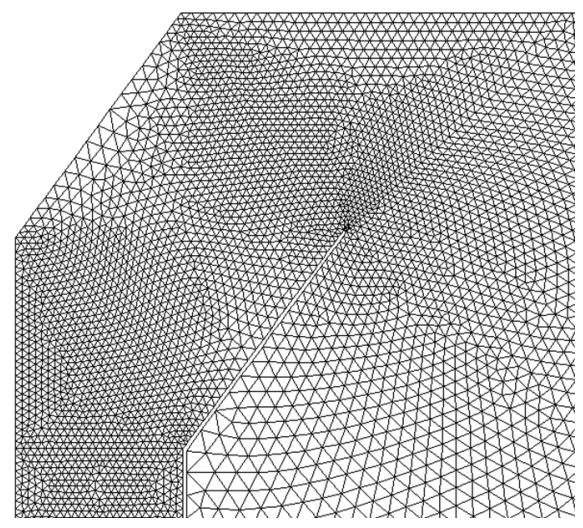

(c)

Figure 5 - Difference between coarse, medium and fine mesh models at impeller outlet for coneshaped deflector (note thickness of draft tube, as well as differing mesh distributions on impeller and digester faces) a) Fine mesh, b) Medium mesh, and c) Coarse mesh 


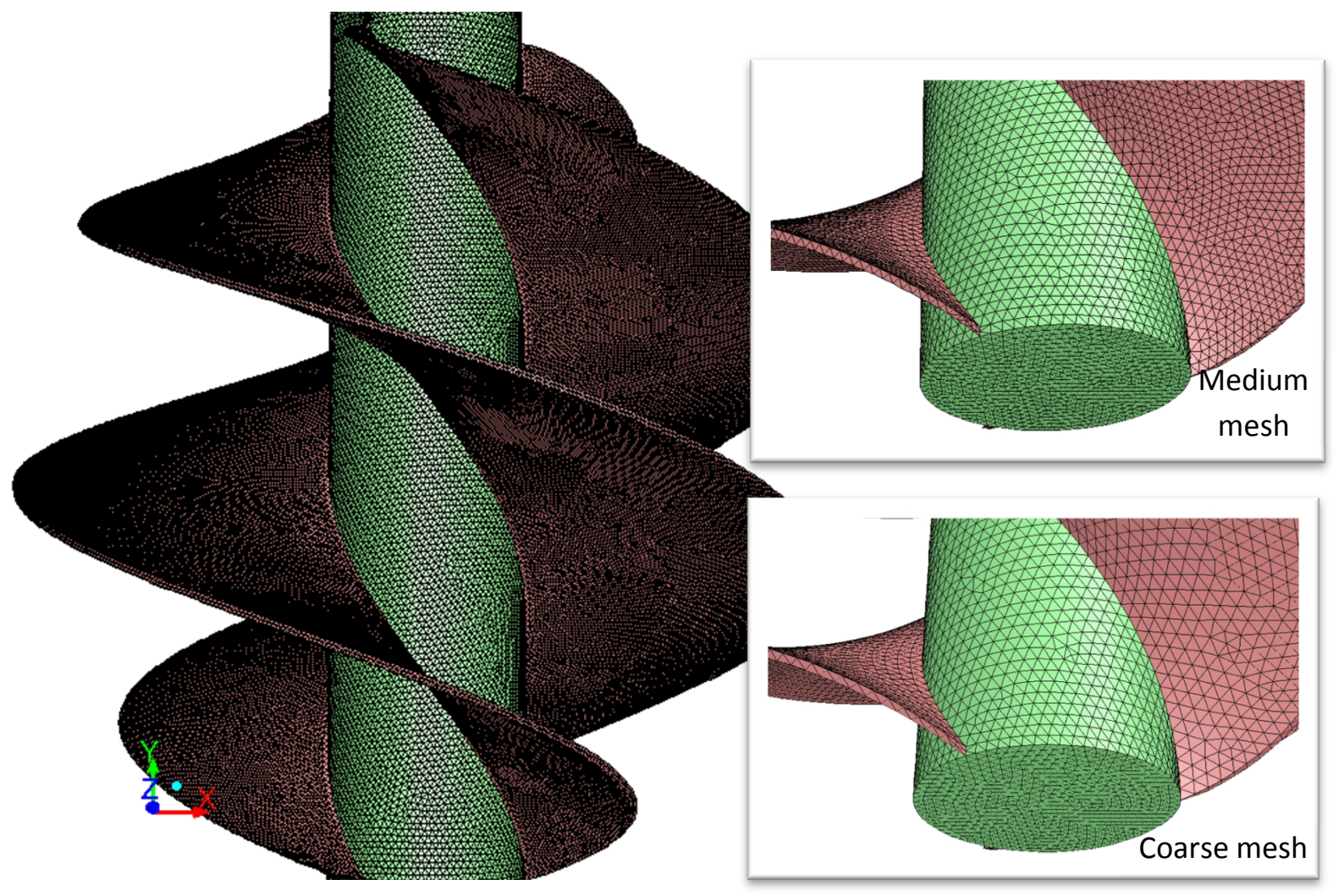

Figure 6 - Fine mesh in the region of the impeller (inserts showing difference between medium and coarse mesh models)

\subsection{Turbulent closure}

The Reynolds number can be based on the impeller characteristics (rotation speed, diameter) or the draft tube and Non-Newtonian characteristics (draft tube diameter, average draft tube velocity, consistency and power-law indices) (Metzner and Reed, 1955). For the current application, with the average draft tube velocity, $V_{a}$ is approximately $3.7 \mathrm{~m} / \mathrm{s}$ based on results presented below. The Reynolds number formulas are (Chen, 1981):

$$
\begin{aligned}
\operatorname{Re}_{\text {impeller }} & =\frac{\rho N D^{2}}{\mu} \text { (water) } \\
\operatorname{Re}_{\text {drafttube }} & =\frac{\rho V_{a}^{2-n} D^{n}}{k(0.75+0.25 / n)^{n} 8^{n-1}} \text { (sludge) }
\end{aligned}
$$




$$
\begin{aligned}
& \operatorname{Re}_{\text {draftube }}=\frac{\rho V_{a} D}{\mu} \text { (water) } \\
& \text { For } \quad \mathrm{N}=500 \mathrm{RPM}=8.33 \mathrm{rev} / \mathrm{s}, \quad \rho=998 \mathrm{~kg} / \mathrm{m}^{3}, \quad \mu=0.001 \mathrm{~Pa} . \mathrm{s}, \quad k=0.5 \mathrm{~Pa} . \mathrm{s}^{n}, \quad n=0.5, \\
& \mathrm{D}=0.6006 \mathrm{~m}, \mathrm{~V}_{\mathrm{a}} \approx 3.7 \mathrm{~m} / \mathrm{s}: \\
& \operatorname{Re}_{\text {impeller }}=3.0 E 6, \operatorname{Re}_{\text {draftube }}=2.8 E 5 \text { (sludge), } \operatorname{Re}_{\text {draftube }}=2.2 E 6 \text { (water) }
\end{aligned}
$$

Wu (2010a) lists 20000 as the turbulent Reynolds number required for full mixing in the digester. Because of the turbulent flow that is present in the domain, use is made of a turbulence model. The SST k- $\omega$ turbulence model is used to provide turbulent closure (ANSYS Fluent, 2010).

\subsection{Impeller treatment}

The MRF (Multiple Reference Frame) modeling method is used to model the rotating impeller. In essence, a different (rotating) reference frame is used for the cell zone enclosing the impeller (see inserts in Figures 3 and 4) than for the rest of the domain (rest of draft tube and digester). The extent of the MRF zone has an influence on the solution because of the treatment of the interface between the zone that is rotating relative to the zones that are stationary. The lower interface of the MRF was chosen to be $195 \mathrm{~mm}$ below the rotating impeller. The upper interface of the MRF was chosen to be in the throat of the impeller draft tube exit as indicated in Figures 3 and $4 a$ ). The effect of the size of the MRF zone was not investigated.

\subsection{Boundary conditions and convergence}

The free surface of the digester was treated as a slip wall (i.e., zero shear stress specified on this boundary). All the other walls were treated as no-slip smooth walls. As the digester is modeled with no inlets or outlets, the flow patterns are established through application of a rotation to the impeller MRF zone. The impeller rotation direction is set to provide upward pumping in normal 
operation. The surface velocities of the impeller and flow deflector are shown in Figures 7 and 8 for the two draft tube configurations considered. In Figure 7, the cone deflector is stationary, while in Figure 8 , it can be seen that the bellmouth-shaped flow deflector is rotating. Convergence is obtained when normalized residuals have stabilized (typically all residuals less than 1E-3 except for $\omega$, less than $5 \mathrm{E}-3$ ) and when the draft tube mass flow rate and impeller torque had stabilized.

\subsection{Mixing criteria}

The U.S. EPA (1979) guideline for the lower limit of power dissipated per unit volume (also called Mixing Energy Level by $\mathrm{Wu}(2010 \mathrm{~b}))$ is between 5 and $8 \mathrm{~W} / \mathrm{m}^{3}$ for complete mixing in pumped circulation anaerobic digesters. In addition, a lower limit of the average velocity gradient (or "Gvalue") of between 50 and $80 \mathrm{~s}^{-1}$ is recommended with a digester turnover time less than the range between 20 and 30 minutes.

\subsection{Mesh independence using $\mathrm{GCl}$}

The Grid Convergence Index (GCI) method (Roach, 1998; ASME V\&V 20, 2009) proceeds in the following way. Given a series of meshes with different sizes, the constant grid refinement ratio, $r$, defines the relationship between successive meshes. If $r=2$, then the mesh is doubled in each of the dimensions represented in the solution domain. Non-integer refinement can also be used as in this study, where $r=2.2$ is used. The aim of grid refinement is to have a solution that is in the so-called asymptotic range, whereby the underlying theory of Richardson Extrapolation is valid asymptotically.

Assume that we can extract a performance parameter, $f$, from a CFD solution that is indicative of the accuracy of the solution. This parameter may be an integrated quantity (like impeller torque) or a performance metric (like the induced draft tube mass flow rate) that represents the intent of the CFD simulation. For three successively refined CFD solutions, we would have $f_{1}, f_{2}$ and $f_{3}$, with $f_{1}$ associated with the finest mesh. The order of convergence, $p$, can then be calculated as 


$$
p=\ln \left(\frac{f_{3}-f_{2}}{f_{2}-f_{1}}\right) / \ln (r)
$$

Richardson Extrapolation, neglecting higher-order terms, gives an estimate of the exact performance parameter (at zero grid spacing), as

$$
f_{h=0}=f_{1}+\frac{f_{1}-f_{2}}{r^{p}-1}=\frac{r^{p} f_{1}-f_{2}}{r^{p}-1} .
$$

The Grid Convergence Index $(G C l)$ of the fine grid is defined as

$$
G C I_{\text {fine }}=\frac{F_{s}|\varepsilon|}{r^{p}-1}
$$

where $F_{s}$ is a factor of safety $\left(F_{s}=1.25\right.$ when a minimum of 3 solutions are available (Roach, 1998)) and the relative error, $\varepsilon$, is

$$
\varepsilon=\frac{f_{2}-f_{1}}{f_{1}} .
$$

When 3 solutions are available, we can calculate $\mathrm{GCl}_{12}$ and $\mathrm{GCl}_{23}$ in a dimensionless form, as

$$
G C I_{12}=\frac{F_{s}\left|\frac{f_{2}-f_{1}}{f_{1}}\right|}{r^{p}-1} \text { and } G C I_{23}=\frac{F_{s}\left|\frac{f_{3}-f_{2}}{f_{2}}\right|}{r^{p}-1} \text {. }
$$

If we are in the asymptotic range of convergence, then

$$
G C I_{23} \approx r^{p} G C I_{12} \text {. }
$$

Therefore, if

$$
\frac{G C I_{23}}{r^{p} G C I_{12}} \approx 1
$$

then mesh independence is achieved. 


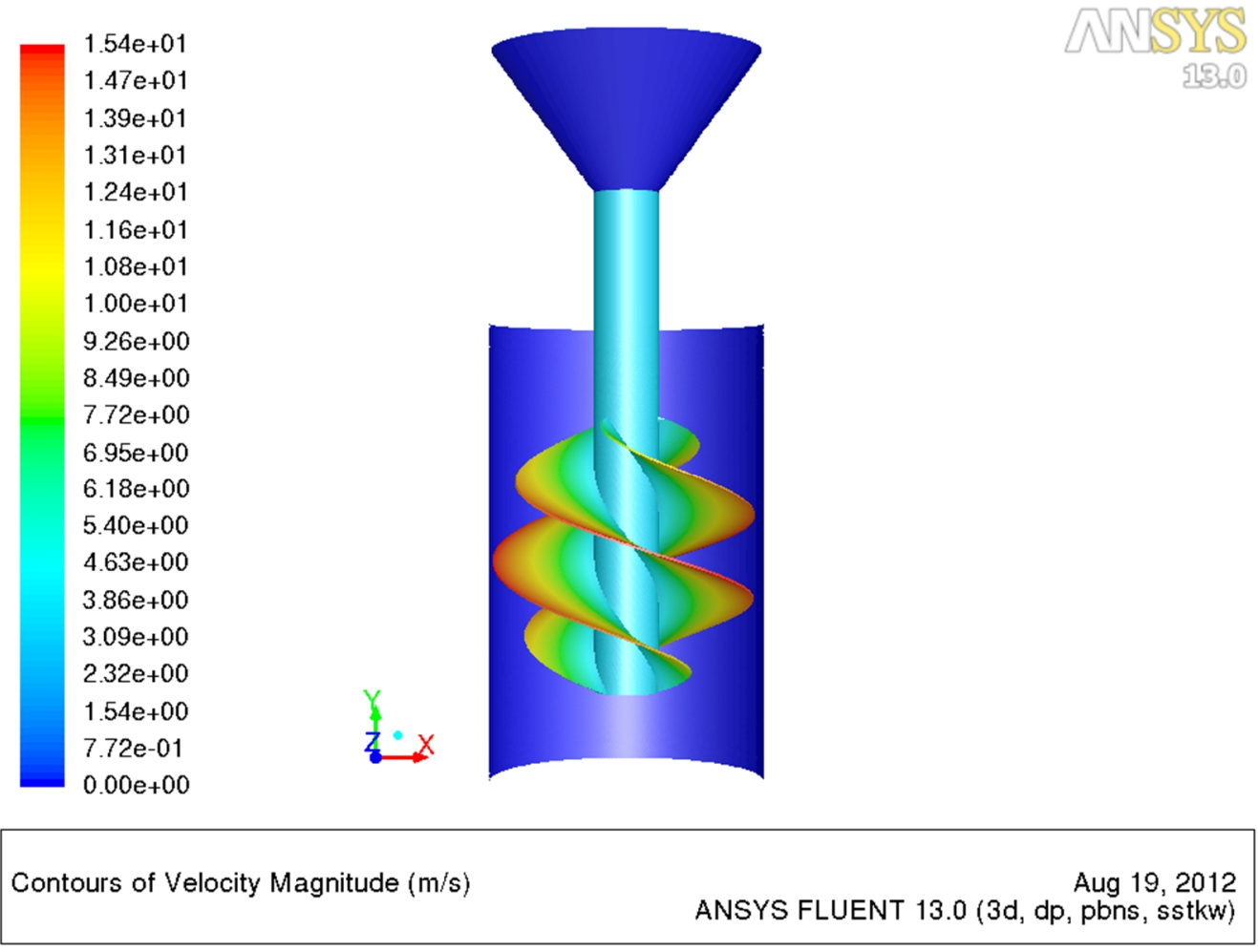

Figure 7 - Velocity magnitude contours on solid surfaces of impeller, shaft and stationary coneshaped flow deflector ( $\mathrm{N}=500 \mathrm{RPM})$

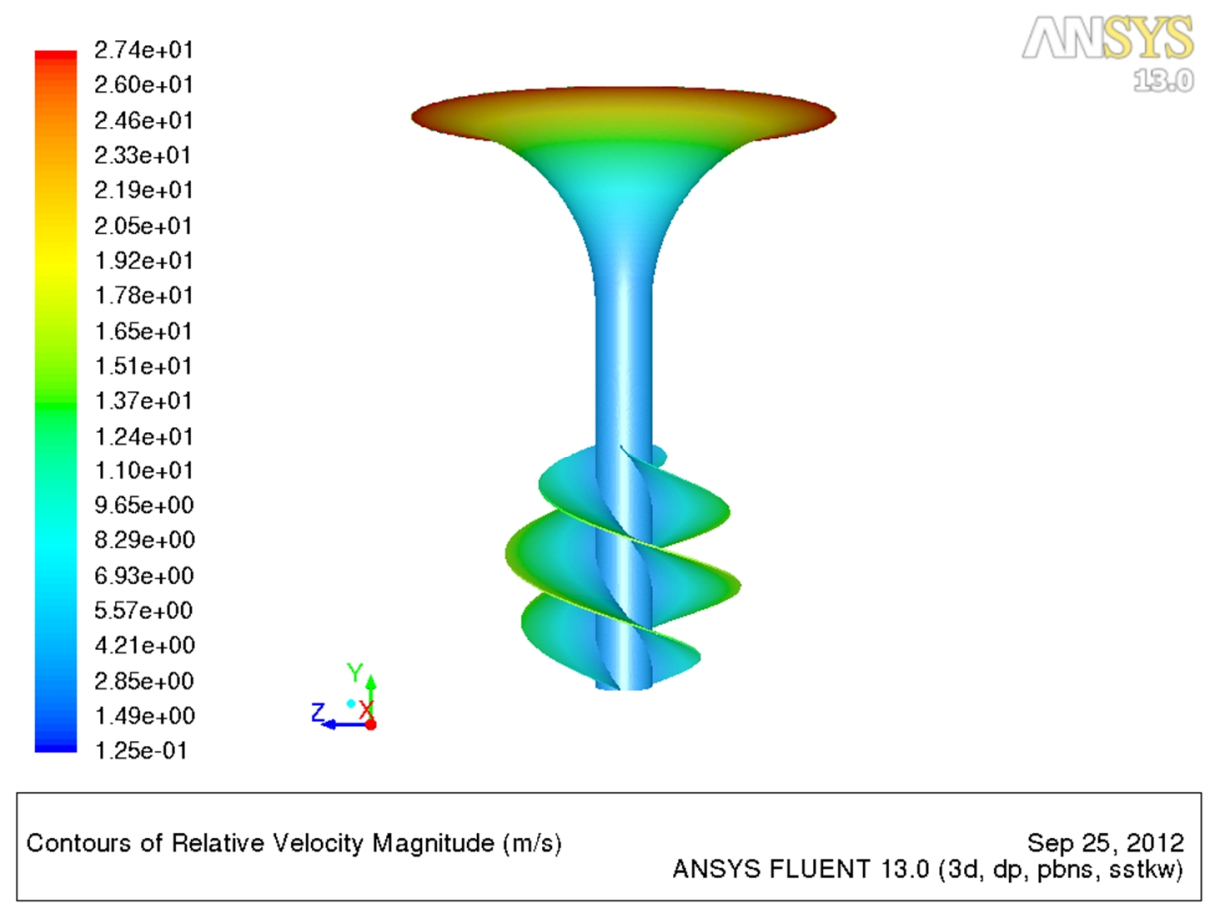

Figure 8-Velocity contours on solid surfaces of impeller, shaft and rotating bellmouth-shaped flow deflector ( $\mathbf{N}=500 R P M)$ 


\section{Results and discussion}

\subsection{Mesh independence and turbulence model}

Water is used as modeling fluid $\left(20^{\circ} \mathrm{C}, 998 \mathrm{~kg} / \mathrm{m}^{3}, 0.001 \mathrm{~Pa} . \mathrm{s}\right)$ when assessing mesh independence and the effect of the choice of turbulence model. An impeller rotation rate of 500RPM is used. Table 3 lists the integrated results obtained when using the coarse, medium and fine mesh described above. The $\mathrm{GCl}$ parameters (draft tube mass flow rate and the impeller torque) as well as the estimates and indices are given in Table 4 using the terms defined in equations (6) to (12). It can be seen that the meshes used are in the asymptotic range (ratio $\sim 1$ ), implying that the fine mesh provides sufficiently accurate results. Although there is not a large change in the integrated quantities with changing mesh resolution, the flow patterns were significantly different. The medium mesh patterns were similar to those obtained using the fine mesh. The CFD solution for the coarse mesh had more difficulty converging on the monitored values, with the values in Table 3 being averaged values over a large range of iterations. The rest of the results presented in the paper are those obtained using the fine mesh.

As discussed in Sections 1 and 2.6, the SST k- $\omega$ turbulence model is chosen for this study based on previous experience and recommendations from other authors. To provide additional support for this choice, the Reynolds Stress turbulence model (RSM) was evaluated for the coarse mesh using water as modeling fluid. The RSM uses 7 additional equations instead of the 2 equations used for the SST k- $\omega$ turbulence model. As illustrated in Table 3, this higher-order turbulent closure provides results that are within $1.5 \%$ of the coarse mesh SST result, justifying the use of the cheaper SST k- $\omega$ turbulence model for the rest of the results in this paper. 


\begin{tabular}{|l|l|l|l|l|}
\hline & $\begin{array}{l}\text { Coarse mesh } \\
\text { SST k- } \omega \text { turbulence } \\
\text { model }\end{array}$ & $\begin{array}{l}\text { Coarse mesh } \\
\text { Reynolds Stress } \\
\text { turbulence model }\end{array}$ & Medium & Fine mesh \\
\hline $\begin{array}{l}\text { Draft tube mass flow rate } \\
\text { [kg/s] }\end{array}$ & 1091 & 1078 & 1078 & 1076 \\
\hline $\begin{array}{l}\text { Steady-state operating } \\
\text { impeller torque [Nm] }\end{array}$ & 264 & 260 & 284 & 279 \\
\hline $\begin{array}{l}\text { Volume turnover time } \\
\text { [min] }\end{array}$ & 19.1 & 19.3 & 19.3 & 19.3 \\
\hline $\begin{array}{l}\text { Velocity gradient (“G- } \\
\left.\text { value”) [s }{ }^{-1}\right]\end{array}$ & 105 & 104 & 109 & 108 \\
\hline $\begin{array}{l}\text { Power dissipated per unit } \\
\text { volume/Mixing Energy } \\
\left.\text { Level [W/m }{ }^{3}\right]\end{array}$ & 11.1 & 10.9 & 11.9 & 11.7 \\
\hline
\end{tabular}

Table 3 - Integrated results for mesh dependency study

\begin{tabular}{|l|l|l|l|l|l|l|l|l|}
\hline Quantity & $f_{3}$ & $f_{2}$ & $f_{1}$ & $p$ & $f_{\mathrm{h}=0}$ & $\mathbf{G C l}_{12}$ & $\mathbf{G C l}_{32}$ & Asymptotic \\
\hline $\begin{array}{l}\text { Draft tube mass flow rate } \\
{[\mathrm{kg} / \mathrm{s}]}\end{array}$ & 1091 & 1078 & 1076 & 2.374 & 1076 & 0.042 & 0.271 & 0.988 \\
\hline $\begin{array}{l}\text { Steady-state operating } \\
\text { impeller torque [Nm] }\end{array}$ & 264 & 284 & 279 & 1.758 & 277 & 0.734 & 3.157 & 1.076 \\
\hline
\end{tabular}

Table 4 - Grid Convergence Index (GCI) parameters and estimates

\subsection{Effect of free surface assumption}

Because of the close proximity of the free surface of the digester to the draft tube outlet (approximately $300 \mathrm{~mm}$ ), it is expected that the impeller jet stream will interact with the free surface 
during operation. The question is how much the deviation in the free-surface level from horizontal will impact the performance estimate of the impeller or the digester mixing performance. The freesurface boundary is modelled as a slip wall, i.e., no resistance (zero shear stress) is imparted by the air above the fluid level to the fluid motion. If the free-surface is forced to remain horizontal, then the fluid flow of the jet is forced to turn in a horizontal direction once it impacts this surface. Apart from resulting in an incorrect jet momentum (direction and magnitude), this could cause an increase in the back pressure of the impeller.

To test the effect of this flat slip-wall assumption, a 2D axi-symmetric CFD simulation was performed with the Volume of Fluid (VOF) method (ANSYS Fluent, 2010) to get an estimate of the free-surface movement for the average draft tube velocity obtained with the 3D CFD model. This transient simulation reached a steady-state free-surface position after about 4 seconds (see Figure 9 for a snapshot at 5.4sec). This position (exported from ANSYS Fluent as a surface) was imported and parameterised as a spline curve in GAMBIT and a body of revolution was formed. A 3D steady-state simulation with this perturbed but fixed free surface was performed to investigate this influence on the impeller performance parameters. The free-surface shape modelled is displayed in Figure 10. A sample result (see Figure 11) for non-Newtonian sludge shows that an unrealistic flow pattern is obtained. The fixed free surface 'slip wall' causes the impeller jet to be deflected downward and attach to the outer surface of the draft tube before ingestion at the bottom of the draft tube. This flow pattern was obtained for both water and non-Newtonian sludge. The impeller torque and draft tube mass flow rate estimates were not influenced substantially for water (less than $6 \%$ ) implying that the draft tube flow is largely unaffected by the digester flow pattern. In order to obtain a more physically realistic representation of the free-surface behaviour, a transient VOF simulation incorporating both sludge and air would need to be performed on the 3D geometry. An added complexity in such a model could be the treatment of a crust (should it form) in terms of its characteristics (motion, break-up. etc.). Such an analysis is outside the scope of the present study. 
For the remainder of the simulations presented in this paper, a flat free surface was assumed as depicted in Figure 1.

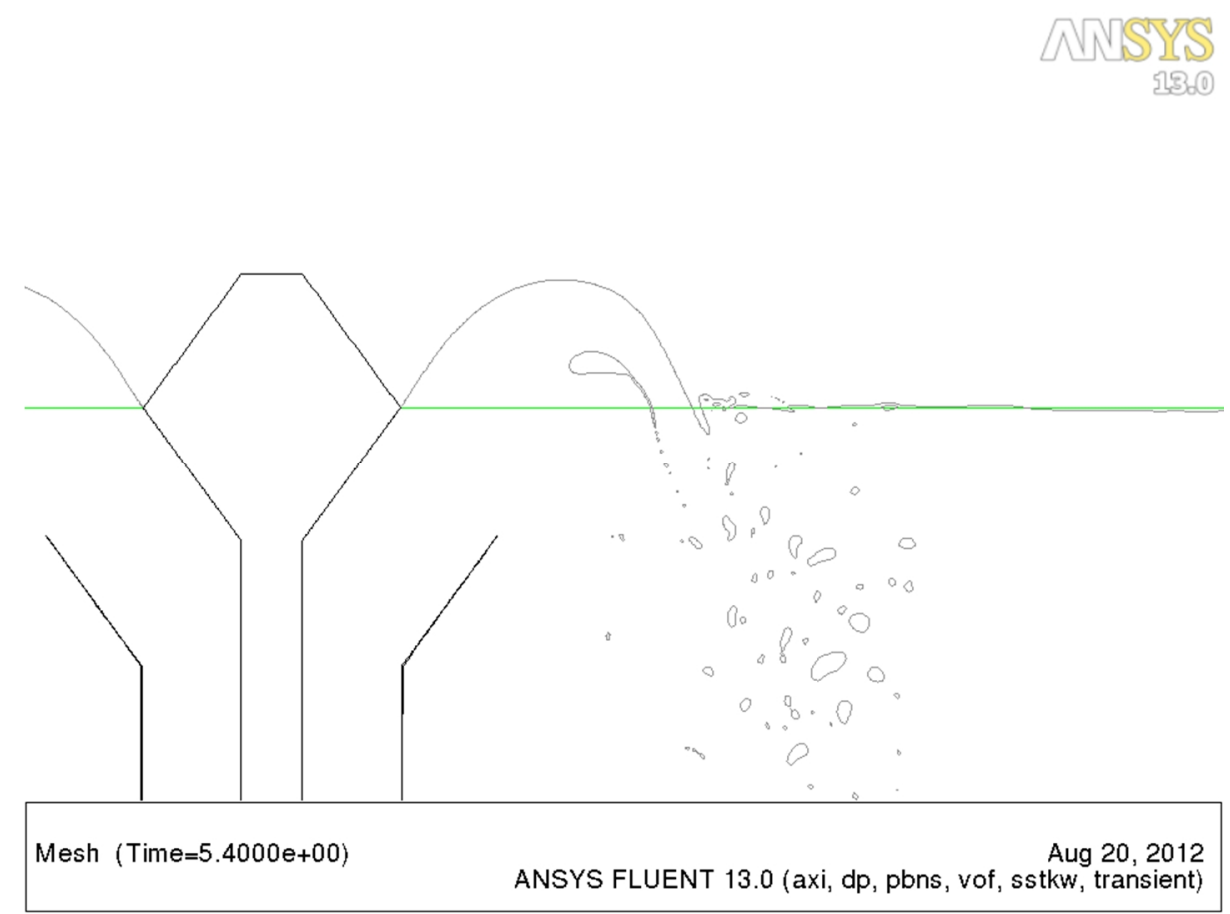

Figure 9 - Free-surface position at $\mathrm{t=5.4s} \mathrm{(2D} \mathrm{Axi-symmetric} \mathrm{model,} \mathrm{no} \mathrm{swirl,} \mathrm{Hershel-Bulkley} \mathrm{non-}$ Newtonian fluid model, $1000 \mathrm{~kg} / \mathrm{s}$ mass flow rate)

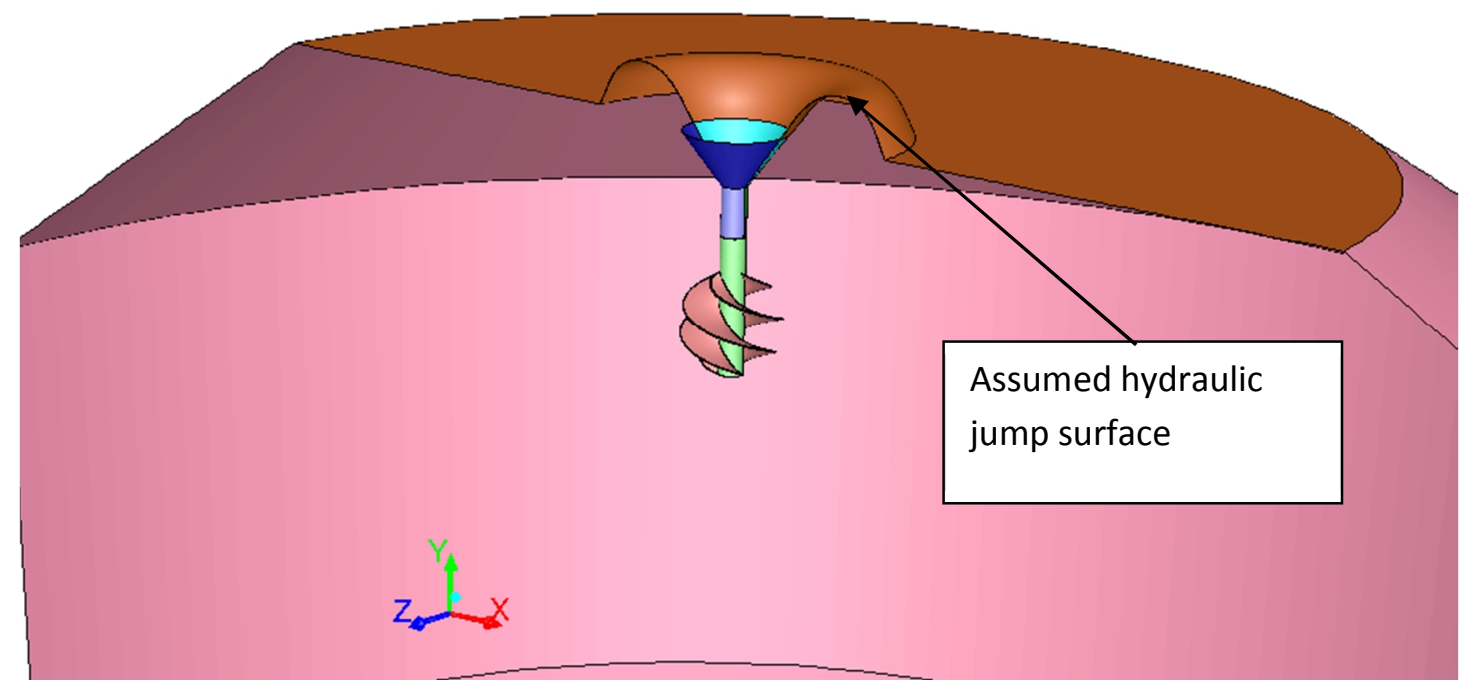

Figure 10 - Modelled free-surface position (symmetric half shown, draft tube not shown for clarity) 


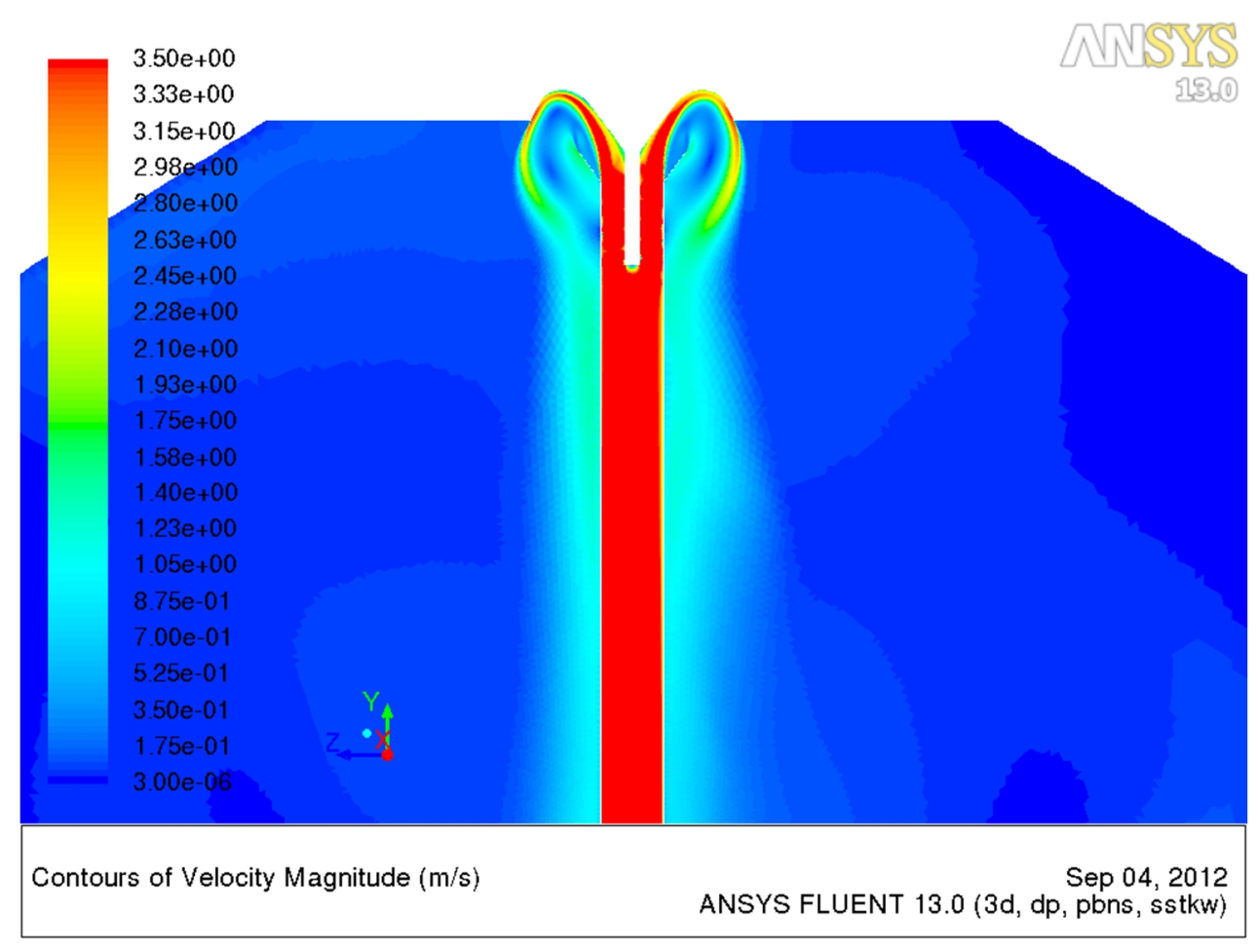

Figure 11 - Velocity magnitude contours (scale limited to $3.5 \mathrm{~m} / \mathrm{s}$ ) for fixed perturbed free-surface position (Hershel-Bulkley Non-Newtonian fluid model, 500RPM)

\subsection{Comparison of draft tube exit geometry}

The main influence of the bellmouth-shaped draft tube exit is to guide the flow from vertical to horizontal with less flow separation (see Figure 12). The influence of the flat free-surface assumption is expected to be smaller as well. Although the flow rate is increased through the draft tube as a result (see Table 4$)$, and the impeller torque is lower $(249 \mathrm{Nm}$ for bellmouth exit versus $306 \mathrm{Nm}$ straight cone), the additional torque required to rotate the flow deflector is significant (values to be given later).

The overall digester flow patterns are similar (see Figure 13) but the bellmouth jet has more momentum and therefore penetrates deeper into the digester than for the straight cone case. The non-Newtonian nature of the sewage sludge can clearly be seen because of the regions where the digester fluid remains stagnant. Using a Newtonian fluid (water) for comparison results in a flow 
pattern where the whole digester forms a nearly symmetric toroidal vortex (Figure 13c). This illustrates the importance of considering non-Newtonian rheology for sewage sludges. Table 5 lists the mixing criteria for the two designs, including the values for water as modeling fluid for comparison. All the criteria for complete mixing are met. Note that although the overall mixing criteria between water and the non-Newtonian fluid are very similar (less than $9 \%$ deviation), the mixing flow patterns are very different. This highlights the fact that digester design should include an analysis such as the current one to evaluate the influence of non-Newtonian fluid behavior. This statement is of increasing importance for cases of higher solids concentration, as has been shown, e.g., by Wu (2010a), due to the increasing non-Newtonian behavior of high solids concentration sludge.

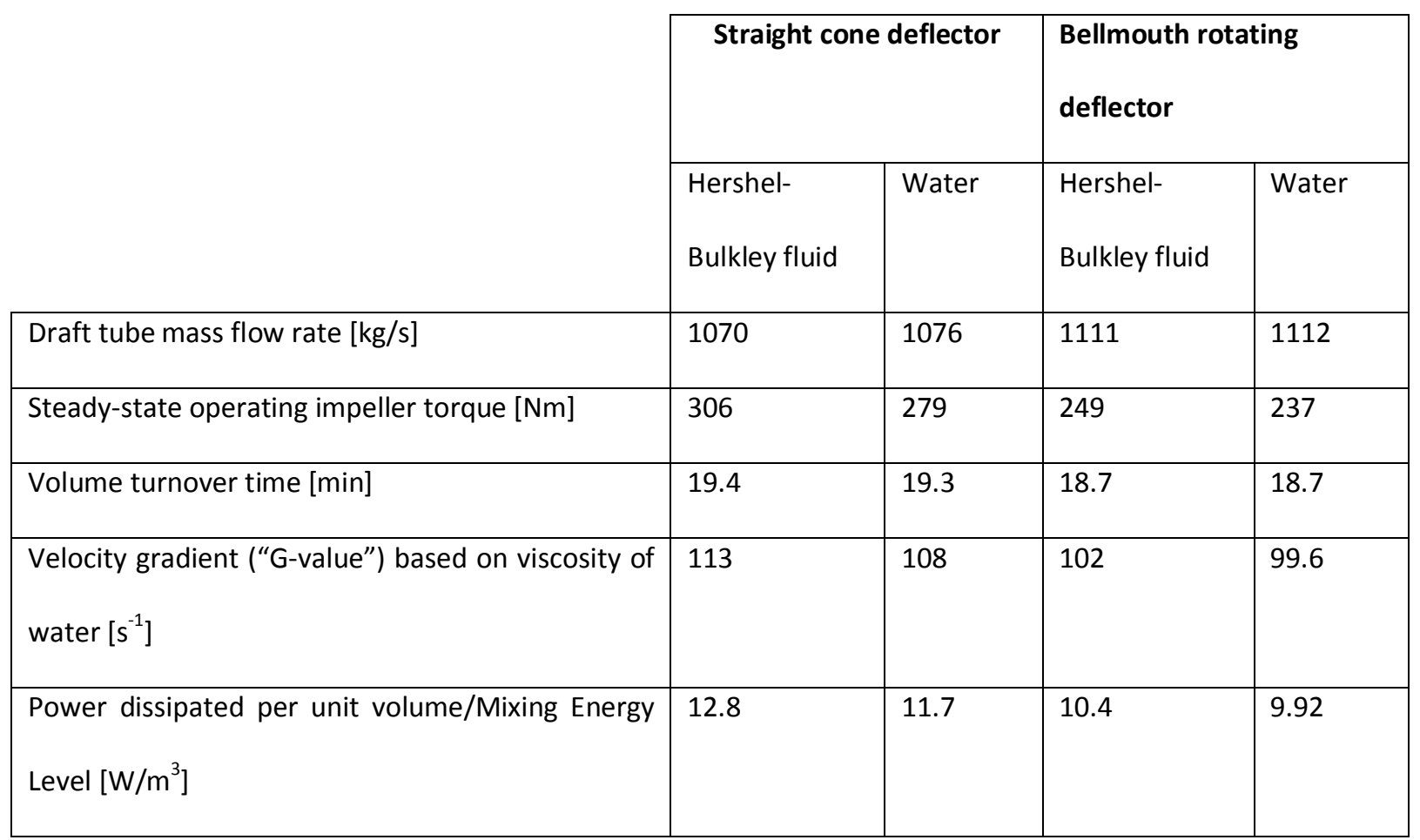

Table 5 - Comparison of integrated quantities for different draft tube exit geometries 


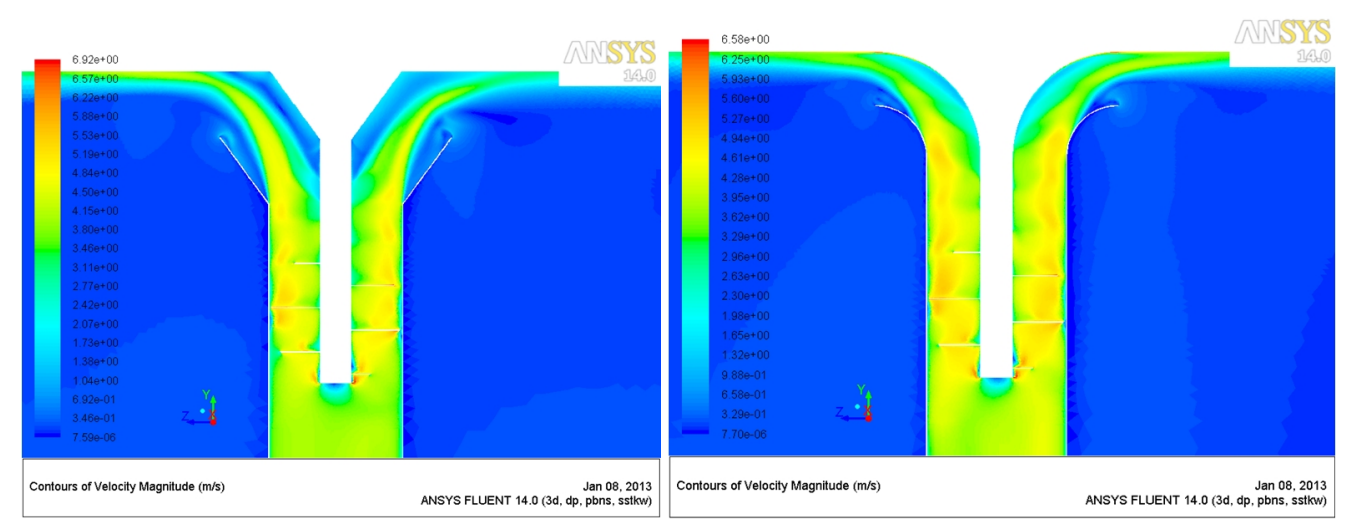

(a)

(b)

Figure 12 - Effect of draft tube exit shape on draft tube flow patterns, Hershel-Bulkley ( $n=0.5$, $k=0.5 \mathrm{~Pa} . \mathrm{s}^{\mathrm{n}}, \tau_{\mathrm{y}}=0.9 \mathrm{~Pa}$ ), N=500RPM: a) Straight cone (stationary deflector), and

b) Bellmouth (rotating deflector)

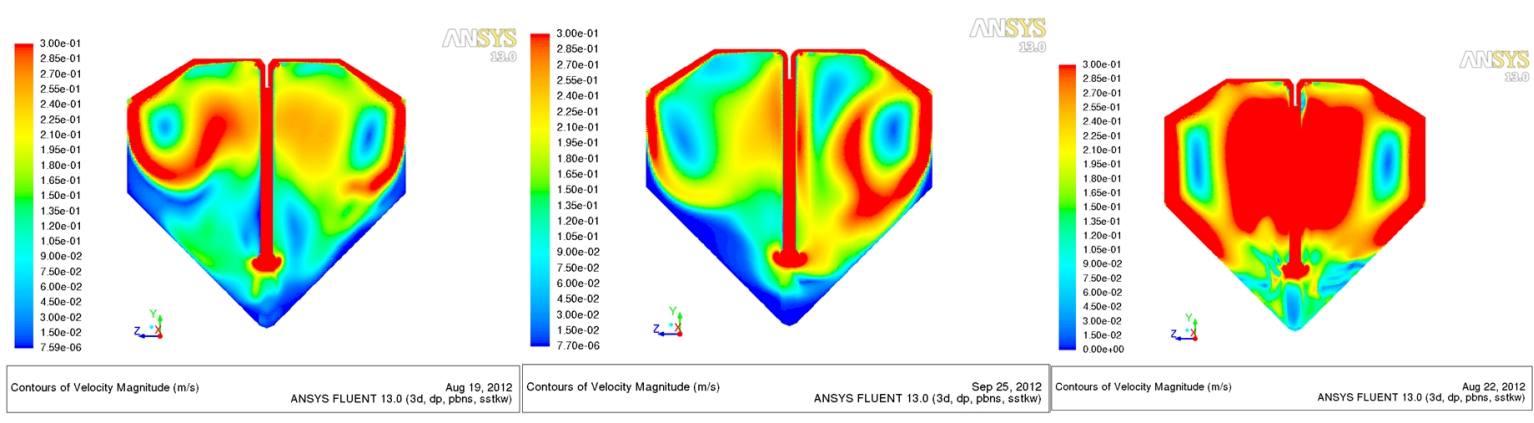

(a)

(b)

(c)

Figure 13 - Effect of draft tube exit shape on overall flow patterns, Hershel-Bulkley $(n=0.5$, $\mathrm{k}=0.5 \mathrm{~Pa} . \mathrm{s}^{\mathrm{n}}, \tau_{\mathrm{y}}=0.9 \mathrm{~Pa}$ ), N=500RPM: a) Straight cone (stationary deflector), b) Bellmouth (rotating deflector), and c) Water, stationary straight cone deflector - All velocity scales clipped at $0.3 \mathrm{~m} / \mathrm{s}$

\subsection{Effect of sludge age}

To study the effect of sludge age, the two single experiment case data from Table 1 were used with the bellmouth-shaped draft tube exit geometry and rotating flow deflector. Of interest here is the viscous torque of the rotating deflector relative to the total torque of the impeller. The slopes of the 
respective fluids' ( 0 versus 40 days) shear stress-strain curves in Figure 1 at high shear rates suggest that the digested sludge would induce a higher viscous drag on the rotating surfaces than that of raw sludge. This is confirmed in Table 6 where the relative contributions to the overall torque are compared. The torque due to normal (pressure) forces on the rotating deflector is negligible and is therefore not listed. The total impeller torque for the raw sludge $(330 \mathrm{Nm})$ in Table 6 is significantly higher than the $249 \mathrm{Nm}$ listed in Table 5 for the averaged properties (Monteiro data fit in Table 1). This is due to the fact that the single experiment data lead to a higher power-law index ( 0.66 versus $0.5)$ and higher consistency index $\left(0.75\right.$ versus $\left.0.5 \mathrm{~Pa} . \mathrm{s}^{n}\right)$ than obtained when averaging the data. The higher yield stress of the averaged data $(0.9$ versus $0.7 \mathrm{~Pa})$ doesn't play a role in the impeller region due to the high shear rates experienced there.

\begin{tabular}{|l|l|l|l|l|l|l|}
\hline Sludge age & Draft tube & Impeller & Impeller & Total & Rotating & Impeller + \\
& mass flow & torque & torque & Impeller & deflector & rotating \\
& rate $[\mathrm{kg} / \mathrm{s}]$ & (pressure & (viscous & torque $[\mathrm{Nm}]$ & torque & deflector \\
& & $\begin{array}{l}\text { component) } \\
\text { component) }\end{array}$ & & $\begin{array}{l}\text { (viscous } \\
\text { component) }\end{array}$ & torque [Nm] \\
& & {$[\mathrm{Nm}]$} & {$[\mathrm{Nm}]$} & & & \\
& 1079 & 261 & 69.7 & 330 & 288 & 618 \\
\hline 0 & 1052 & 273 & 122 & 395 & 381 & 776 \\
\hline 40 & & & & & & \\
\hline
\end{tabular}

Table 6 - Comparison of torque contributions for variation in sludge age

The influence of rotating the flow deflector on the total required torque is significant, and for reduced operating costs, having this bellmouth deflector stationary should be investigated.

The influence of sludge age on the flow patterns is displayed in Figure 14. For the raw sludge, the overall stress-strain behavior is higher than for digested sludge, which should 
imply that the overall digester should be easier to mix when containing digested sludge. The mixing zone for the raw sludge (Figure 14a)) doesn't extend as far down as for the digested sludge case (Figure 14b)). The latter mixing pattern is also more symmetrical, implying more even mixing.

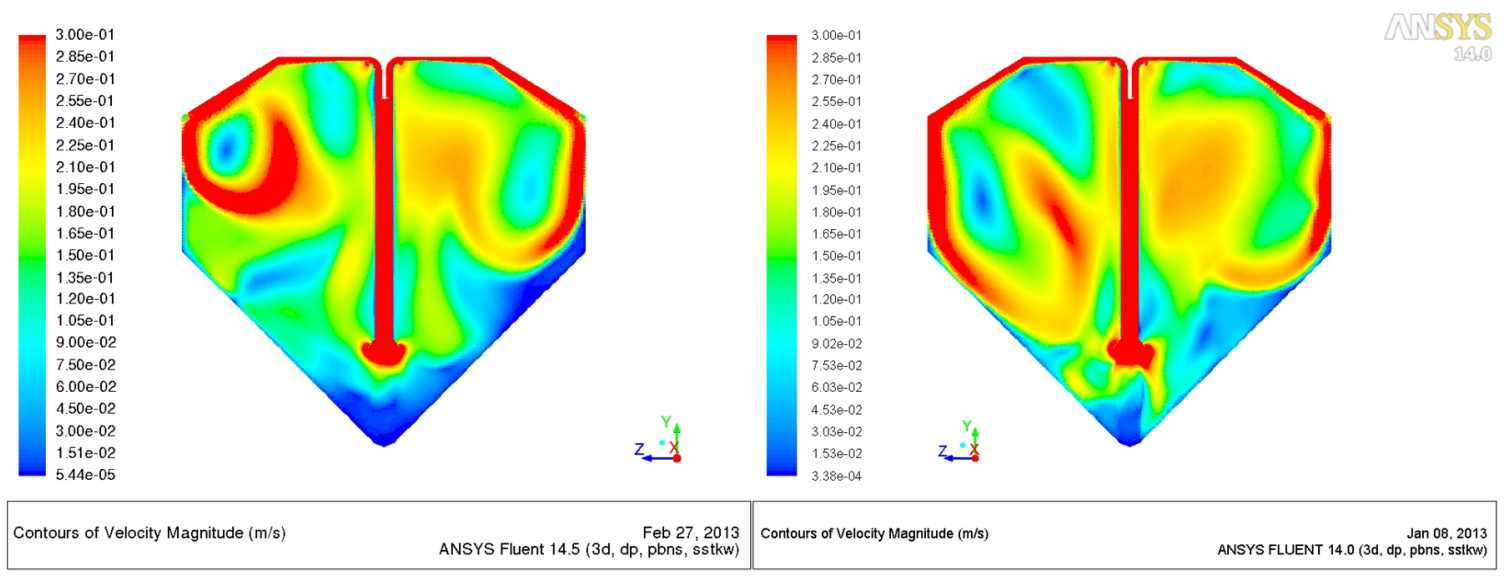

(a)

(b)

Figure 14 - Effect of sludge age on overall flow patterns, N=500RPM: a) Raw sludge, and

b) Digested sludge - All velocity scales clipped at $0.3 \mathrm{~m} / \mathrm{s}$

The strain rate of the fluid adjacent to the impeller and shaft surface is depicted in Figure 15. It can be seen that the digested sludge induces a higher strain rate, explaining the higher torque in Table 6 due to a higher associated shear stress. For comparison, the Monteiroaveraged data case for raw sludge is also shown in Figure 15c). Here the strain rate values are lower due to the lower consistency index and power-law index (Table 1), explaining the lower torque value in Table 5. All plots in Figure 15 are capped at a strain rate of $3000 \mathrm{~s}^{-1}$ for comparison. It should be noted that the sources used for the rheological fluid properties (Monteiro, 1997 and Baudez et al., 2011) only report strain rates up to $1000 \mathrm{~s}^{-1}$. It is not known whether the fluid will continue to adhere to the Hershel-Bulkley law above this value. High shear rate performance is discussed in Baudez et al. (2011). They mention that digested 
sludge behaves as a shear-thinning yield stress fluid with a plateau viscosity at high shear rates. In other words, it follows the Bingham law described in equation (1). Monteiro (1997) also published Bingham law fits to his data. Figure 16 compares the high strain rate behavior of the two laws (Hershel-Bulkley and Bingham) based on Monteiro's averaged data for raw ( 0 days) and digested (40 days) sludge. Note how the two Hershel-Bulkley curves cross over at around $1700 \mathrm{~s}^{-1}$ strain rate, while the Bingham curves remain parallel on the log-log plot because of the constant plastic viscosities of the two fluids.

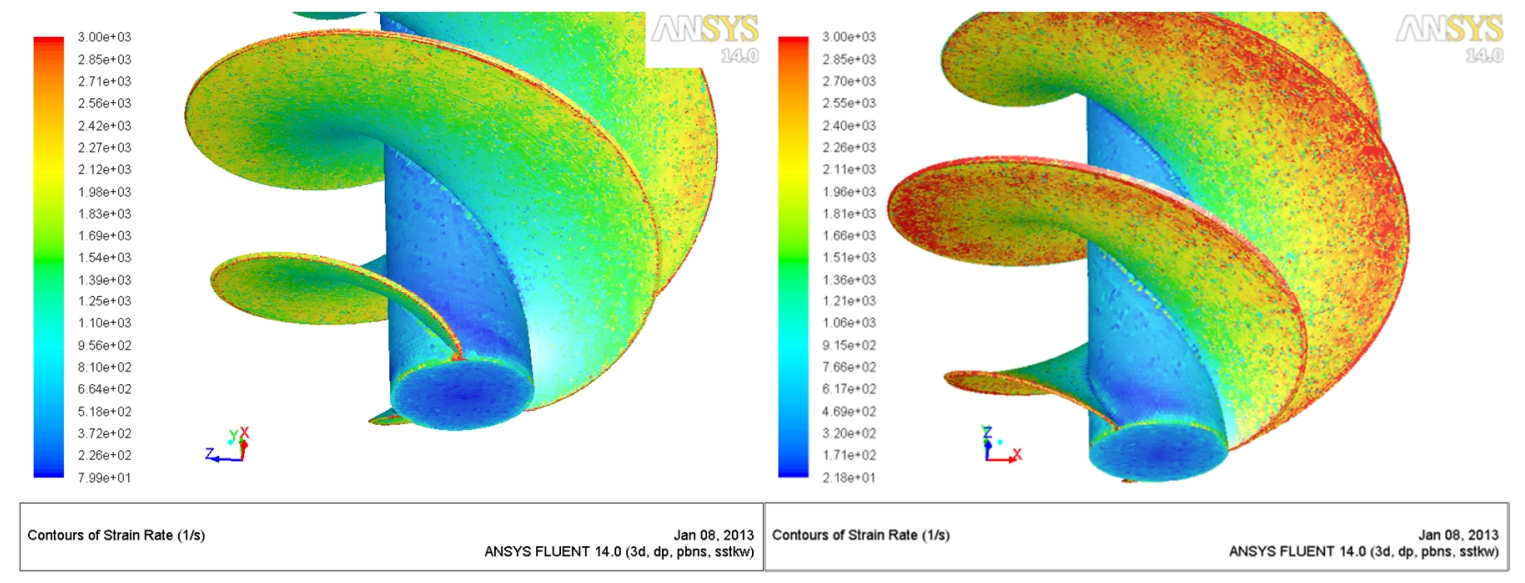

(a)

(b)

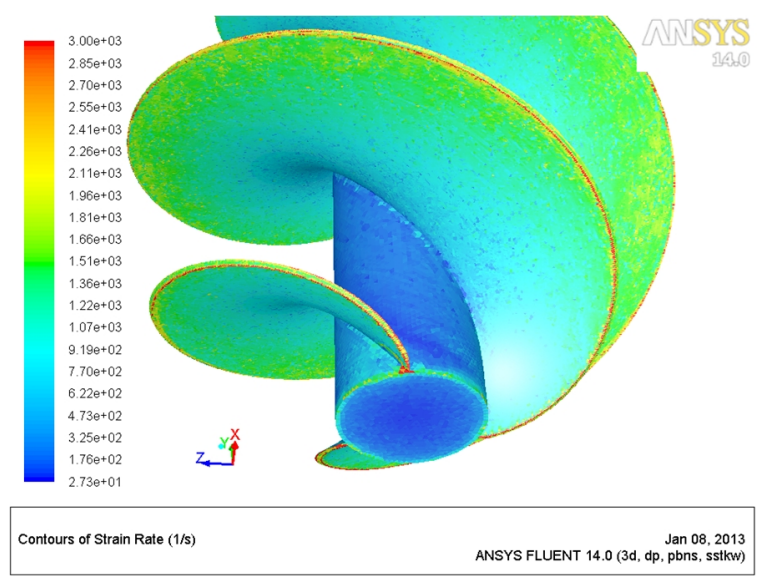

(c)

Figure 15 - Strain rate plots, N=500RPM: a) Raw sludge (single experiment), b) Digested sludge (single experiment), and c) Raw sludge (averaged data) - All scales clipped at $3000 \mathrm{~s}^{-1}$ 


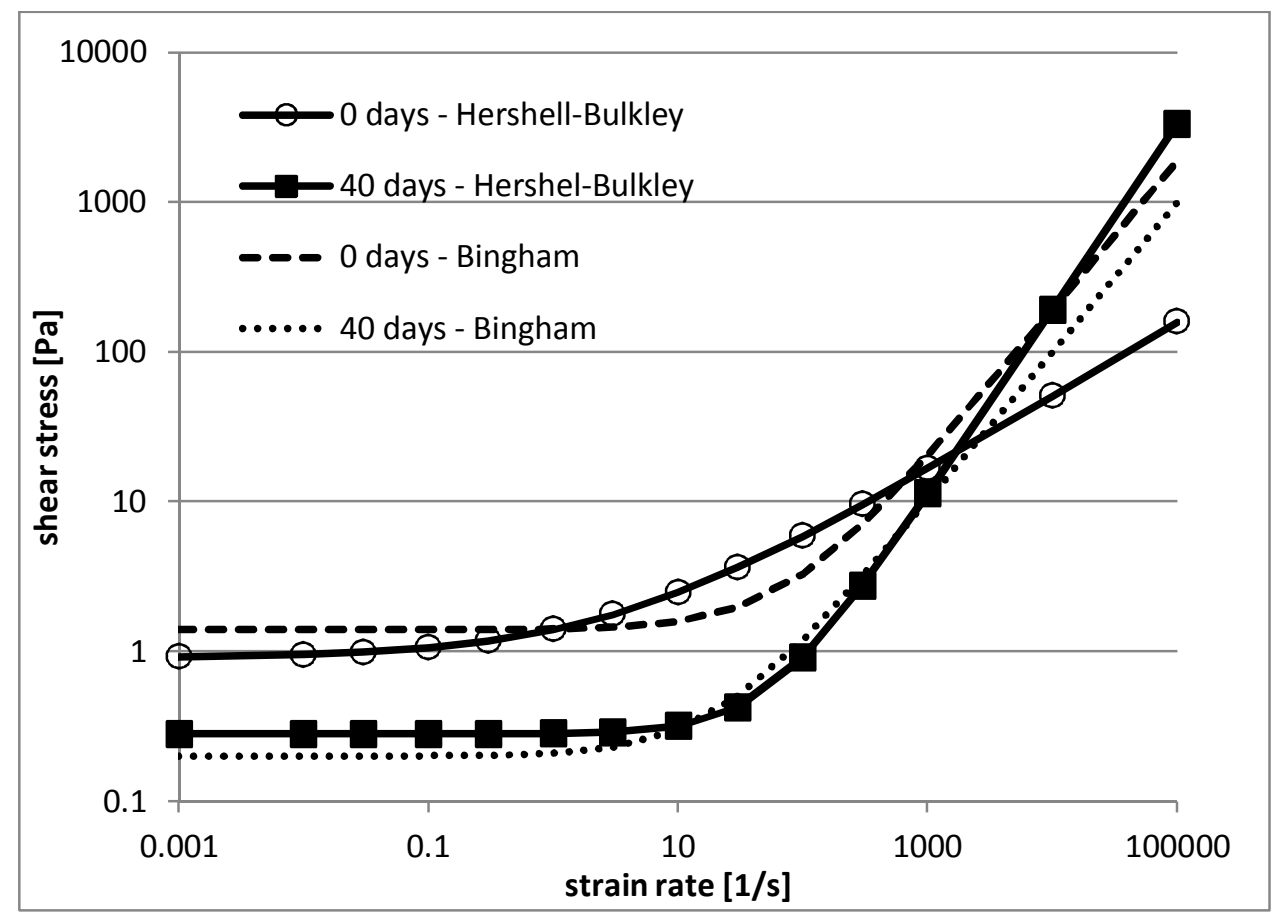

Figure 16 - Shear Stress - Strain rate plots: Hershel-Bulkley versus Bingham law (Data from Monteiro (1997))

\section{Conclusions}

The paper has discussed the application of CFD to model anaerobic digester performance for sewage sludge. Mechanical mixing was provided through the use of an impeller situated in a centrallylocated draft tube. The focus of the study was on considering the sewage sludge as a non-Newtonian fluid following the Hershel-Bulkley law and how this rheological behavior would influence both digester mixing performance and impeller torque requirements. The effect of sludge age (raw versus digested) was considered. The following conclusions can be drawn from the study:

1. As also found by other researchers, sludge rheology has a large influence on the mixing patterns prevalent in the digester. The comparison of Newtonian water with non-Newtonian sludge showed that symmetrical mixing patterns with the whole of the digester being 
brought into motion in a predictable fashion is possible for water. For sludge, the mixing pattern was influenced by the yield stress property of the fluid, leading to more zones that are close to being stationary in the lower parts of the digester.

2. Sludge age has a significant influence on the torque required to turn the impeller. In general, the stress-strain curve for digested sludge lies below that of raw sludge, implying that it should be easier to mix at the lower strain rates experienced in the digester. Because of the higher slope of the Hershel-Bulkley law stress-strain curve at high shear rates for digested sludge however, the impeller absorbs more torque for digested sludge. This fact makes it crucial that the fluid properties of the sludge be known accurately when designing the system. It is shown that when using the Bingham law, the digested sludge rheology curve remains below that of raw sludge.

3. Mesh independence of the integrated results (draft tube mass flow rate and steady-state operating impeller torque) was illustrated using the Grid Convergence Index (GCl) method. Fine mesh results are reported in the paper, because although the integrated quantities of impeller torque and draft tube mass flow rate were within the asymptotic range for all three mesh resolutions, the flow patterns in the digester were markedly different.

4. Although the emphasis of this paper was not on evaluating different turbulence models, it was shown that the SST k- $\omega$ turbulence model gave similar results as the Reynolds Stress turbulence model on a coarse mesh when using water as modeling fluid.

5. The modification of the flow deflector above the draft tube exit from a straight stationary cone to a rotating bellmouth shape had two main effects. The first was an improvement of the flow by limiting the separation of flow at the draft tube exit, resulting in a lower impeller torque and higher draft tube mass flow rate. The second effect was detrimental in that the torque required to turn the rotating bellmouth flow deflector was nearly the same as that required to turn the impeller. The main reason for this is the large diameter of the 
bellmouth. A solution to this problem could be to investigate the effect of a stationary bellmouth deflector.

\section{Acknowledgements}

The authors would like to acknowledge Westinghouse Electric South Africa for the use of their computational facilities during this research.

\section{References}

Achkari-Begdouri, A., Goodrich, P.R., 1992. Rheological properties of Moroccan dairy cattle manure. Bioresource Technology 40, 149-156.

ANSYS Fluent 13.0 User's Guide, November 2010.

ASME V\&V 20 - 2009, 2009. Standard for Verification and Validation in Computational Fluid Dynamics and Heat Transfer, American Society of Mechanical Engineers, ISBN 9780791832097.

Bakker, C.W., Meyer, C.J., Deglon, D.A., 2009. Numerical modeling of non-Newtonian slurry in a mechanical flotation cell. Minerals Engineering 22, 944-950.

Baudez, J.C., Markis, F., Eshtiaghi, N., Slatter, P., 2011. The rheological behavior of anaerobic digested sludge. Water Research 45, 5675-5680.

Bridgeman, J., 2012. Computational fluid dynamics modeling of sewage sludge mixing in an anaerobic digester. Advances in Engineering Software 44, 54-62.

Chen, Y.R., 1981. Impeller power consumption in mixing livestock manure slurries. Transactions of the ASAE 24(1), 187-192.

Kritzinger, H.P., 2010. Hydrodynamics of a monolithic stirrer reactor. PhD thesis, Technical University Delft.

Meroney, R.N., 2009. CFD simulation of mechanical draft tube mixing in anaerobic digester tanks. Water Research 43(4), 1040-1050. 
Metzner, A.B., Reed, J.C., 1955. Flow of non-Newtonian fluids-correlation of laminar, transition and turbulent-flow regions. AIChE J 1 (4), 434-440.

Monteiro, P.S., 1997. The influence of the anaerobic digestion process on the sewage sludges rheological behaviour. Water Science and Technology 36 (11), 61-67.

Roache, P.J., 1998. Verification and Validation in Computational Science and Engineering, Hermosa Publishers, Albuquerque, New Mexico.

Terashima, M., Goel, R., Komatsu, K., Yasui, H., Takahashi, H., Li, Y.Y. and Noike, T., 2009. CFD simulation of mixing in anaerobic digesters. Bioresource Technology 100 (7), 2228-2233.

U.S. Environmental Protection Agency, 1979. Process Design Manual for Sludge Treatment and Disposal (EPA/625/1-79/011). Cincinnati, OH.

Wu, B., Chen, S., 2008. CFD simulation of non-Newtonian fluid flow in anaerobic digesters. Biotechnology and Bioengineering 99 (3), 700-711.

Wu, B., 2010a. CFD simulation of mixing in egg-shaped anaerobic digesters. Water Research 44, 15071519.

Wu, B., 2010b. Computational Fluid Dynamics investigation of turbulence models for non-Newtonian fluid flow in anaerobic digesters. Environmental Science and Technology 44 (23), 8989-8995.

Wu, B., 2010c. CFD prediction of mixing time in anaerobic digesters. Transactions of the ASABE 53 (2), 553563.

Wu, B., 2011. CFD investigation of turbulence models for mechanical agitation of non-Newtonian fluids in anaerobic digesters. Water Research 45, 2082-2094.

Wu, B., 2012a. Large Eddy Simulation of mechanical mixing in anaerobic digesters. Biotechnology and Bioengineering 109 (3), 804-812.

Yu, L., Ma, J., Chen, S., 2011. Numerical simulation of mechanical mixing in a high solid anaerobic digester. Bioresearch Technology 102 (2), 1012-1018. 